\title{
Establishment and management of woody seedlings in gullies in a semi-arid environment (Tigray, Ethiopia)
}

\author{
Bert Reubens • Jean Poesen - Jan Nyssen • \\ Yves Leduc • Amanuel Z. Abraha • \\ Sarah Tewoldeberhan $\cdot$ Hans Bauer • \\ Kindeya Gebrehiwot • Jozef Deckers • Bart Muys
}

Received: 28 February 2009 / Accepted: 28 June 2009 / Published online: 21 July 2009

(C) Springer Science + Business Media B.V. 2009

\begin{abstract}
In the north Ethiopian highlands, gully erosion is a significant land degradation process. Although the protective role of vegetation has been demonstrated in many studies, efforts previously made in using woody species for erosion control in the research area are limited, and when applied,
\end{abstract}

Responsible Editor: Alexia Stokes.

B. Reubens $\cdot$ Y. Leduc $\cdot$ B. Muys $(\bowtie)$

Division Forest, Nature and Landscape,

Katholieke Universiteit Leuven,

Celestijnenlaan 200 E, Box 2411, 3001 Leuven, Belgium

e-mail: bart.muys@ees.kuleuven.be

B. Reubens

e-mail: bert.reubens@ees.kuleuven.be

J. Poesen

Physical and Regional Geography Research Group,

Katholieke Universiteit Leuven,

Celestijnenlaan 200 E, Box 2409, 3001 Leuven, Belgium

J. Nyssen

Department of Geography, Ghent University,

Krijgslaan $281 \mathrm{~S} 8$,

9000 Ghent, Belgium

A. Z. Abraha $\cdot$ S. Tewoldeberhan $\cdot$ K. Gebrehiwot Land Resources Management and Environmental Protection Department, Mekelle University, P.O. Box 231, Mekelle, Ethiopia

H. Bauer · J. Deckers

Division Soil and Water Management,

Katholieke Universiteit Leuven,

Celestijnenlaan 200 E, Box 2411, 3001 Leuven, Belgium survival of the planted seedlings was very low. Lack of experience and fundamental knowledge on species autecology and traits are two important bottlenecks. This study therefore aims at better understanding seedling establishment and growth in a context of tree plantings, with the view to further control gully erosion in a semi-arid environment. To this end survival, growth and development of seedlings of Acacia etbaica Schweinf., Sesbania sesban (L.) Merr. and Dodonaea angustifolia L.f. were monitored during 26 months in a field trial under different site conditions and treatments. The experiment was established at two sites characterized by topographic and edaphic conditions (Vertisol and sandy colluvium) representative for the study area. At each site, seedlings were subjected to different treatments of watering, sheltering and planting position (gully floor, sidewall and shoulder), and a large set of plant growth variables was regularly monitored. Height and biomass growth was fastest for Sesbania, even if affected by different pests. Regardless of the species, plants growing in the (nutrient-rich) Vertisol site had a higher survival rate and an overall better development. Shelter protection significantly increased survival and resulted in taller seedlings. Notwithstanding these general trends, treatment effects were often varying over time and strongly influenced by specific edaphic conditions. Generally, Acacia performed best on gully shoulder and wall, Sesbania on the gully floor and Dodonaea on shoulder positions. Recommendations for planting practice and follow-up research are discussed. 
Keywords Autecology · Growth regulation - Gully

Plant establishment $\cdot$ Acacia etbaica $\cdot$ Sesbania

sesban Dodonaea angustifolia

\section{Introduction}

In the north Ethiopian highlands intense land degradation and deforestation have had and continue to have important effects on loss of topsoil by sheet, rill and gully erosion as well as on landsliding (Nyssen et al. 2004). Such processes result in an irreversible loss of soil fertility and constitute a severe threat for sustainable agriculture and forestry, especially in developing countries (Karambiri et al. 2003). Gully erosion is responsible for significant on-site soil losses, and once developed, gullies transfer runoff and sediment rapidly from uplands to lowlands and further down the drainage system, resulting in off-site consequences such as flooding and sediment deposition in river channels and reservoirs (Haregeweyn et al. 2008; Poesen et al. 2003).

There exists no such thing as a universally suited measure against gullying. To prevent gullying or to rehabilitate or stabilize an existing gully, it is important to first understand its principle causes and dynamics, and to take into account local soil and environmental conditions (Roose et al. 2000). The construction of physical structures such as dry masonry or gabion check dams is the most widely used gully control technique applied in northern Ethiopia. Nevertheless, these structures become less effective over time, and in some situations the check dams lead to piping in the gully sidewalls and concentrated flow bypassing the dam (Nyssen et al. 2004). Moreover, check dams often lead to increased gully bed erosion downstream because of a "clear water effect" (Boix-Fayos et al. 2007; Castillo et al. 2007). Correct design and construction, careful maintenance, and complementary techniques are therefore needed (Nyssen et al. 2004). In that context, biological measures complementing physical structures could result in sustainable and effective control.

The protective role of vegetation has long been recognized and proven: vegetation reduces water erosion by intercepting rainfall, increasing water infiltration, reducing runoff volume and velocity, and stabilizing the soil by roots (e.g. De Baets et al. 2006; Gyssels et al. 2005; Nilaweera and Nutalaya
1999; Reubens et al. 2007). Since different types of vegetation have different effects, depending for example on the depth, strength and density of their rooting system (Nilaweera and Nutalaya 1999; Reubens et al. 2007; Roose et al. 2000), a mixture of species to control a wide range of soil loss processes is generally most beneficial (Reubens et al. 2007). Trees in particular are useful in integrated, multipurpose management practices, as they generally perform a wide range of socio-economic, ecological and cultural functions. This versatility makes them highly appropriate for curbing land degradation in northern Ethiopia.

The most basic solution would be to fence or guard certain areas along gullies, allowing natural vegetation restoration. However, bottlenecks for natural regeneration in semi-arid areas like this are seed (dispersal) limitation, recruitment limitation (especially along gullies abiotic growth conditions are difficult) or a combination of these factors (Aerts et al. 2006; Jordano and Godoy 2002). To catalyze recovery and because of the general shortage of land as well as the huge need for valuable wood products in the study area (Nyssen et al. 2008; Taddese 2001), such a set-aside strategy should include managed planting of high value multipurpose woody species mixed with naturally regenerating vegetation.

At present, vegetative management of gully erosion is rarely implemented in northern Ethiopia since it requires a substantial effort and careful protective management that is not always realistic given the still very widespread free-grazing system (Taddese et al. 2002). Moreover, for many woody species detailed knowledge on species autecology (i.e. the relation and interactions with its environment) and functional traits is currently missing. In order to effectively implement vegetative measures, more fundamental knowledge and more experience are needed with regard to species suitability, bottlenecks impeding plant establishment, and suitability of treatments and growth conditions, especially in the critical initial growth stages. This study therefore aims at better understanding seedling establishment and growth in a context of tree plantings, with the view to further control gully erosion in a semi-arid environment. To this end we studied the survival, growth and development of three important multifunctional species (Acacia etbaica Schweinf, Sesbania sesban (L.) Merr. and Dodonaea angustifolia L.f.) under a set of representative site 
conditions and plant treatments, in order to a) assess species-specific seedling establishment and growth characteristics in a nutrient-rich and nutrient-poor situation; b) identify effects of specific treatments on seedling establishment and growth in both situations; c) understand changes of growth and effects through time; and d) assess type and magnitude of seedling growth bottlenecks. From those insights, we intend to provide some general principles, rules and recommendations for species management in the presented context, in order to define efficient planting practices for further erosion control.

\section{Materials and methods}

Study area

The study area $\left(13^{\circ} 84^{\prime} \mathrm{N}, 39^{\circ} 81^{\prime} \mathrm{E}\right)$ is located in the Dogu'a Tembien woreda (district) in the Central Zone of the Tigray Regional National State, northern Ethiopia, ca. $50 \mathrm{~km}$ west of Mekelle (Fig. 1a). Elevations range between 2,200 $\mathrm{m}$ and 2,600 m above sea level, and local geological formations, comprising limestone, sandstone and Tertiary basalt flows, form sub horizontal layers and give rise to stepped slope profiles (Nyssen et al. 2004). The average yearly precipitation is $778 \mathrm{~mm}$ and the main rainy season ( $>80 \%$ of the yearly rainfall) lasts from mid-June to mid-September, preceded by a less predictable smaller rainy season between March and May. Average monthly temperatures range from $4-6^{\circ} \mathrm{C}$ minimum to $20-22^{\circ} \mathrm{C}$ maximum (Nyssen et al. 2008). Agriculture in Dogu'a Tembien consists exclusively of small-scale family farms. On average, the families in the study area use two or three parcels of cropland, with a combined area between 0.5 ha and 0.75 ha. Grassland, rangeland and exclosures (i.e. areas where natural vegetation is protected from the intrusion of humans or livestock; Aerts et al. 2009) are communally owned (Nyssen et al. 2008).

Species selection

Three woody species were carefully selected for experimentation, manageable within the project time, space and budget constraints. The initial selection of these species was based on a multi-criteria decision approach taking into account indicators of ecological suitability, socio-economical functions, protection functions and root characteristics. To enable such an approach, a comprehensive tree species database was developed for northern Ethiopia, based on scientific as well as local ecological knowledge, that provided information on species-related characteristics and that enabled assessment of the relative importance of selection criteria (Moeremans 2007). Given the context of usage for gully reclamation, the main criteria used were drought resistance as well as resistance to temporary water logging, fast aboveand belowground development, socio-economic relevance, and local availability of seedlings.

The selected species have the following characteristics (based on Bekelle-Tesemma 1993; Dharani 2002; Fichtl and Admasu 1994; Maundu and Tengnäs 2005; Noad and Birnie 1989; Royal Botanic Gardens 2007; World Agroforestry Centre 2002):

1. Acacia etbaica Schweinf. [Tigrigna (local language): seraw; E: no common English name] is a monoecious tree or shrub, indigenous and very common in the research area. It is a leguminous, calciphyl and drought-resistant species, having re-sprouting characteristics and a good capacity to be used for recovering degraded land. A. etbaica is an important source of good firewood, providing also the pillars and beams to hold the heavy earthen roofs of houses in northern Ethiopia. Vegetative propagation is perfectly possible.

2. Sesbania sesban (L.) Merr. [Tigrigna: sesbania; E: River bean or Egyptian rattle pod] is an exotic but naturalized, very fast growing shrub and a prolific seeder, under natural conditions found along rivers or in moist or swampy sites. It tolerates dry eroded soil as well as seasonal or permanently waterlogged, saline, acidic and alkaline soil conditions. S. sesban is a nitrogen-fixing soil fertility improver, also having the ability to stabilize the soil with its deep taproot system. It is especially known for high-quality green manure and fodder, but also serves as a source of firewood and charcoal, as light construction wood or for making ropes. It is sensitive to several infections and diseases.

3. Dodonaea angustifolia L.f. [Tigrigna: tahses; E: Hop bush or Sand olive] is an indigenous tree or shrub growing in a variety of habitats from riverine forest to shallow, rocky soils or arid marginal areas. 
a

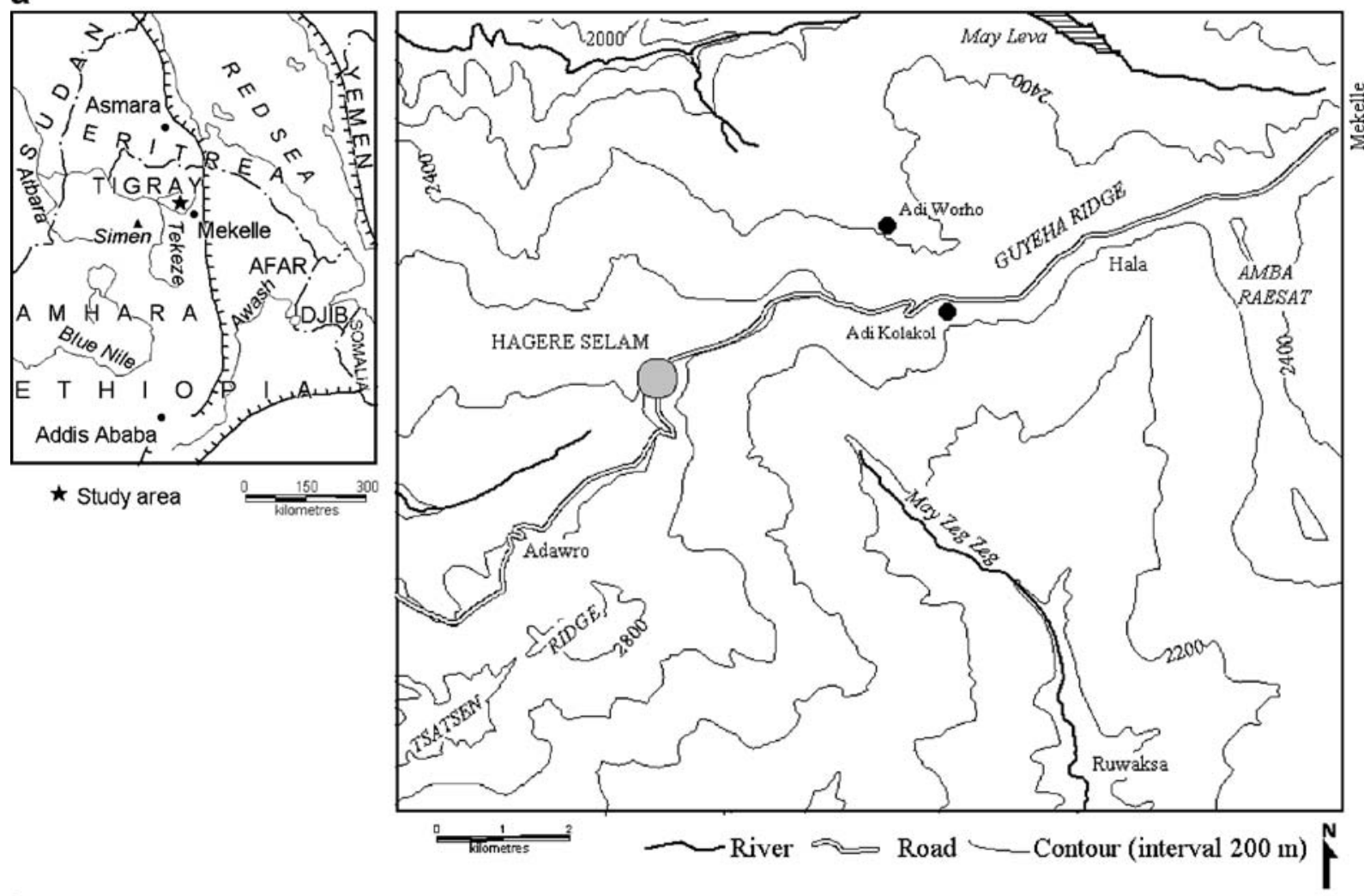

b

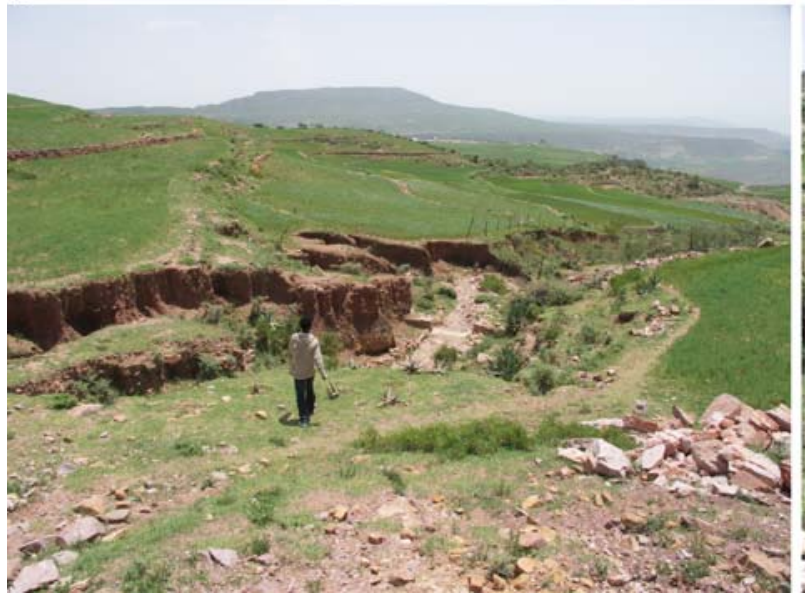

Fig. 1 Study area and experimental sites. a Map location of the study area. b Overview of both study sites comprising the fenced gully parts: Left $=$ Adi Kolakol gully in sandy

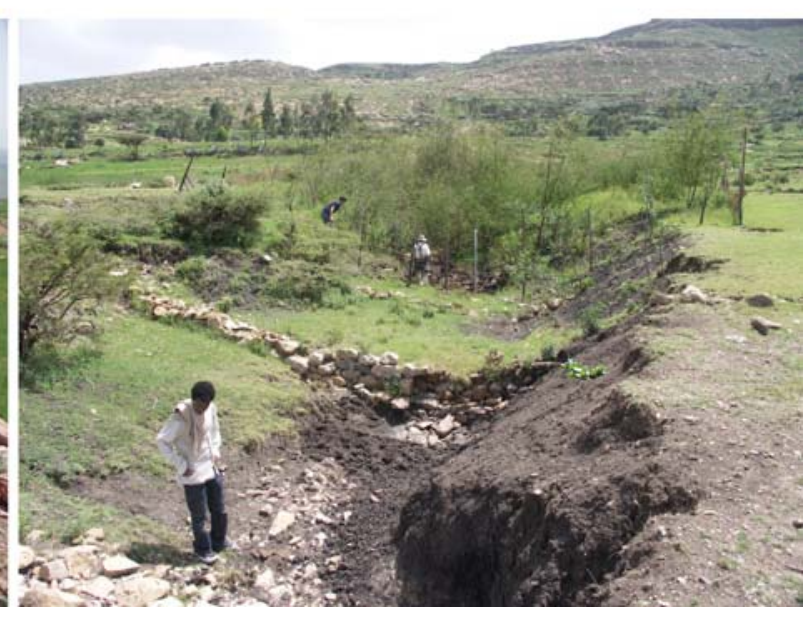

colluvium, Right $=$ Adi Worho gully in Vertisol, with steep limestone cliff in the background
It grows and regenerates easily, and can be an aggressive colonizer. Nevertheless, it is an interesting, drought-resistant soil improver and a good hedge species for dry areas. Its extensive shallow root system makes it also useful for effective erosion control. Furthermore, D. angustifolia is an important bee plant, providing good quality firewood and charcoal as well as hard and heavy wood used for poles, timber, tool handles and walking sticks, and has wide-ranging medicinal uses. 
Prior to transplanting to the field, all seedlings were raised at the Endayesus tree nursery (Mekelle University) in small polyethylene tubes $(5.25 \mathrm{~cm}$ diameter, $15 \mathrm{~cm}$ deep) filled with a substrate of local black soil and sieved river sand mixed with organic material. The open bottom of the polyethylene tubes allowed undisturbed taproot growth and prevented the development of long lateral roots. In the field, seedlings were planted with the substrate attached to the roots but without the polyethylene tubes. At the time of transplanting, seedling age was 17 months, 3 months and 8 months for the Acacia, Sesbania and Dodonaea seedlings, respectively. Despite these relatively large differences in age, average length of all seedlings was ca. $20 \mathrm{~cm}$ at the time of transplanting, and taproot length did not exceed $17 \mathrm{~cm}$. Measurements started in August 2006, and the results of the first 26 months (until October 2008), including three rainy seasons, are presented here.

Site selection and description

The experiments were conducted in two kushets (villages): Adi Kolakol and Adi Worho, further referred to as AK and AW respectively (see Fig. 1). Sites were selected in agreement with the local communities and with suitable gully dimensions and homogeneity in soil as well as environmental conditions as most important selection criteria (Table 1).

The site in AK comprises a gully developed in a soil consisting mainly of sandy colluvium (average thickness around $1.5 \mathrm{~m}$ ) covering a Vertisol. This gully is situated downstream from a culvert of the Mekelle-Adwa road (Fig. 1a) and has been the subject of a road impact study (Nyssen et al. 2002). Absolute peak runoff discharge recorded during the observation period was $1.85 \mathrm{~m}^{3} \mathrm{~s}^{-1}$, corresponding to an absolute maximum water level of $50 \mathrm{~cm}$ in the gully floor. Initiated by the road culvert, this gully is still active. The gully side wall slope is relatively steep $\left( \pm 60^{\circ}\right)$ in the upper part, but gradually reduces towards the lower part of the site (Fig. 1b).

In $\mathrm{AW}$, the site with a gully is located in a lower slope position. Peak runoff discharge recorded during the experiment was $1.90 \mathrm{~m}^{3} \mathrm{~s}^{-1}$, corresponding to an absolute maximum water level of $52 \mathrm{~cm}$ in the gully floor. This active gully is a well-developed channel, initiated in a Calcic Vertisol at the bottom of a steep limestone cliff. Expansion is partially caused by piping. The gully side-wall is sloping $\left(35-60^{\circ}\right)$ along its entire length (Fig. 1b). At both sites, prior overgrazing resulted in a degraded natural vegetation cover. No side-wall reshaping took place.

\section{Experimental setup}

Both field trial sites (each approximately $950 \mathrm{~m}^{2}$ ) were fenced to prevent destruction by grazing, browsing or trampling (see Fig. 1b). Within these sites, the tree seedlings were planted inside and on the shoulder (i.e. the soil surface bordering the gully channel) of the gully, following a systematic planting design (Fig. 2b). Four experimental treatment factors, expected to have an influence on seedling establishment and growth, were taken into account: (a) species (three levels); (b) watering (Water; two levels: low and high volume of manual watering during the dry season); (c) sheltering (Shelter; two levels: unsheltered seedlings versus seedlings individually protected by an open, ca. $35 \mathrm{~cm}$ high shelter of dry Giant reed [Arundo donax L.] stalks - see Fig. 3); and (d) gully position (Position; three levels: gully floor, gully sidewall, and gully shoulder). Sheltering resulted in an average illuminance reduction of $65 \%$, as compared to unsheltered seedlings (measured with a photovoltaic luxmeter-data not shown). Watering volumes were determined through testing and feedback evaluation. At the onset of the experiment, seedlings of low and high watering treatment received 11 and 41 twice a week respectively. When initial survival was assured, these volumes were gradually reduced to 01 and 1.51 twice a week after 1 year. No water was provided during the main rainy season.

At each site, seedlings were planted in an organized way, repeated over six 'experimental plots' running across the gully channel (Fig. 2b). Every such plot consisted of 72 seedlings, equally distributed over the three species, the two shelter treatments and the three gully position treatments. Of the six experimental plots, three full plots received a high and three a low volume of water, which finally resulted in 12 replicates per speciestreatment combination. The same setup was repeated at both sites. 
Table 1 Summary of gully site characteristics

\begin{tabular}{|c|c|c|c|}
\hline Variable & Adi Kolakol & Adi Worho & P-value \\
\hline \multicolumn{4}{|l|}{ Environmental characterisation } \\
\hline Altitude (m a.s.1.) & 2425 & 2260 & \\
\hline Hillslope inclination $\left({ }^{\circ}\right)$ & 17 & 8.5 & \\
\hline Hillslope aspect $(-)$ & SE & NNE & \\
\hline Catchment area (ha) & 8.0 & 45.0 & \\
\hline Surrounding landuse $(-)$ & rangeland \& cropland & rangeland & \\
\hline Yearly rainfall (mm year-1) (2006-2008) & 630 & 800 & \\
\hline Average monthly min air temperature $\left({ }^{\circ} \mathrm{C}\right)(2006-2008)$ & 11.0 & 12.8 & \\
\hline Average monthly max air temperature $\left({ }^{\circ} \mathrm{C}\right)(2006-2008)$ & 24.6 & 29.4 & \\
\hline Peak flow discharge $\left(\mathrm{m}^{3} \mathrm{~s}-1\right)$ & 1.85 & 1.90 & \\
\hline Peak flow shear stress $(\mathrm{Pa})$ & 1434 & 754 & \\
\hline \multicolumn{4}{|l|}{ Soil characterisation (mean \pm s.d.) } \\
\hline Soil water content ( $g \mathrm{~g}-1)$ dry period & $0.080 \pm 0.004$ & $0.134 \pm 0.003$ & $<0.001 * *$ \\
\hline Soil water content ( $g$ g-1) wet period & $0.159 \pm 0.005$ & $0.236 \pm 0.005$ & $<0.001 * *$ \\
\hline Soil bulk density $(\mathrm{g} \mathrm{cm}-3)$ & $1.52 \pm 0.23$ & $1.20 \pm 0.13$ & $<0.001^{* *}$ \\
\hline Clay $(\%)$ & $32.37 \pm 2.15$ & $41.89 \pm 2.15$ & $0.007 * *$ \\
\hline Silt (\%) & $26.46 \pm 1.34$ & $38.55 \pm 1.34$ & $<0.001 * *$ \\
\hline Sand $(\%)$ & $41.46 \pm 2.65$ & $19.57 \pm 2.65$ & $<0.001 * *$ \\
\hline $\mathrm{pH}-\mathrm{H} 2 \mathrm{O}$ & $6.84 \pm 0.53$ & $7.21 \pm 0.11$ & $0.049 *$ \\
\hline Pav (ppm) & $1.46 \pm 0.59$ & $1.99 \pm 1.38$ & 0.376 \\
\hline $\mathrm{CaCO} 3$ - equivalent (g/100 g) & $2.18 \pm 1.72$ & $17.73 \pm 4.59$ & $<0.001 * *$ \\
\hline $\mathrm{ECw}(\mu \mathrm{S} \cdot \mathrm{cm}-1)$ & $109.68 \pm 37.64$ & $202.20 \pm 106.64$ & $0.019^{*}$ \\
\hline CEC (cmolc/kg soil) & $17.29 \pm 5.12$ & $49.49 \pm 4.40$ & $<0.001 * *$ \\
\hline $\mathrm{K}$ (cmolc/kg soil) & $0.44 \pm 0.10$ & $0.83 \pm 0.15$ & $<0.001 * *$ \\
\hline $\mathrm{Ca}$ (cmolc/kg soil) & $15.97 \pm 5.41$ & $40.47 \pm 2.73$ & $<0.001 * *$ \\
\hline $\mathrm{Mg}$ (cmolc/kg soil) & $1.21 \pm 0.34$ & $9.75 \pm 3.64$ & $<0.001 * *$ \\
\hline Corg (g/100 g) & $0.57 \pm 0.08$ & $1.70 \pm 0.32$ & $<0.001 * *$ \\
\hline Ntot (g/100 g) & $0.064 \pm 0.006$ & $0.085 \pm 0.006$ & $0.035^{*}$ \\
\hline
\end{tabular}

Pav available phosphorus; ECw Electrical conductivity; CEC Cation Exchange capacity; Corg Organic carbon; Ntot total nitrogen $* P<0.05 ; * * P<0.01$

Evaluation methodology

\section{Environmental and soil conditions}

A broad set of soil and environmental variables was measured to characterize between-site and within-site heterogeneity.

Rainfall (using five rain gauges) and minimum and maximum air temperature (in two locally constructed, well-ventilated Stevenson shelters) were monitored on a daily basis throughout the duration of the experiment, following the methodology of Nyssen et al.
(2005). In the rainy season, runoff discharge in the gullies at both sites was measured during every rainfall event. To this end, a rectangular masonry channel $2 \mathrm{~m}$ wide and $10 \mathrm{~m}$ long was shaped in the gully floor immediately upstream of the fenced sites. Repeated measurements of flood height and width, as well as mean flow velocity (by recording the travelling time of a floating object between the start and endpoint of the channel) allowed calculating instant discharge. At both sites slope gradient (with a clinometer), aspect (using a compass), gully morphology (e.g. local expansion, wall slope and orientation), 
a

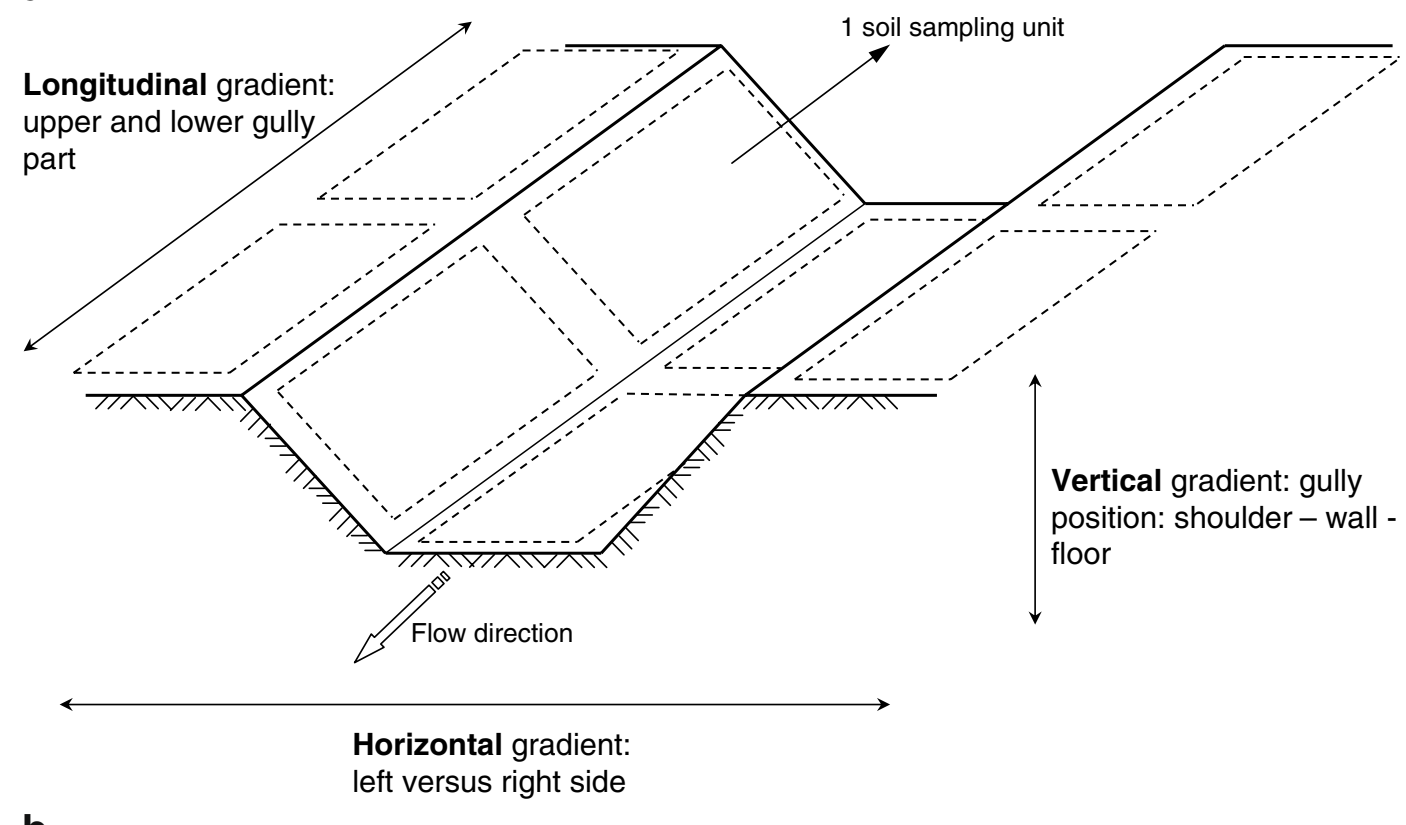

b

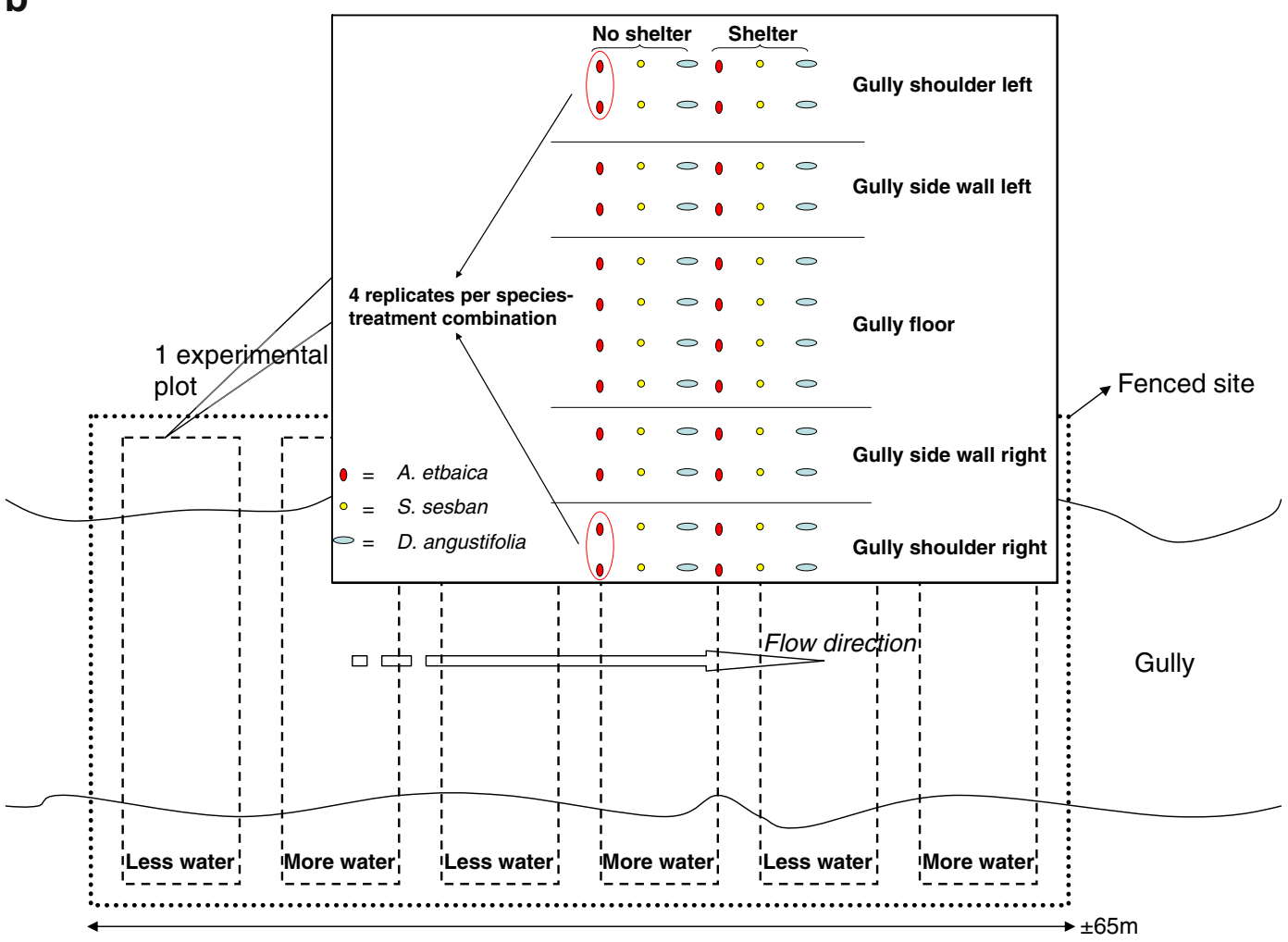

Fig. 2 Experimental setup at each gully. a location of ten soil sampling units, $\mathbf{b}$ treatment setup with six experimental plots 

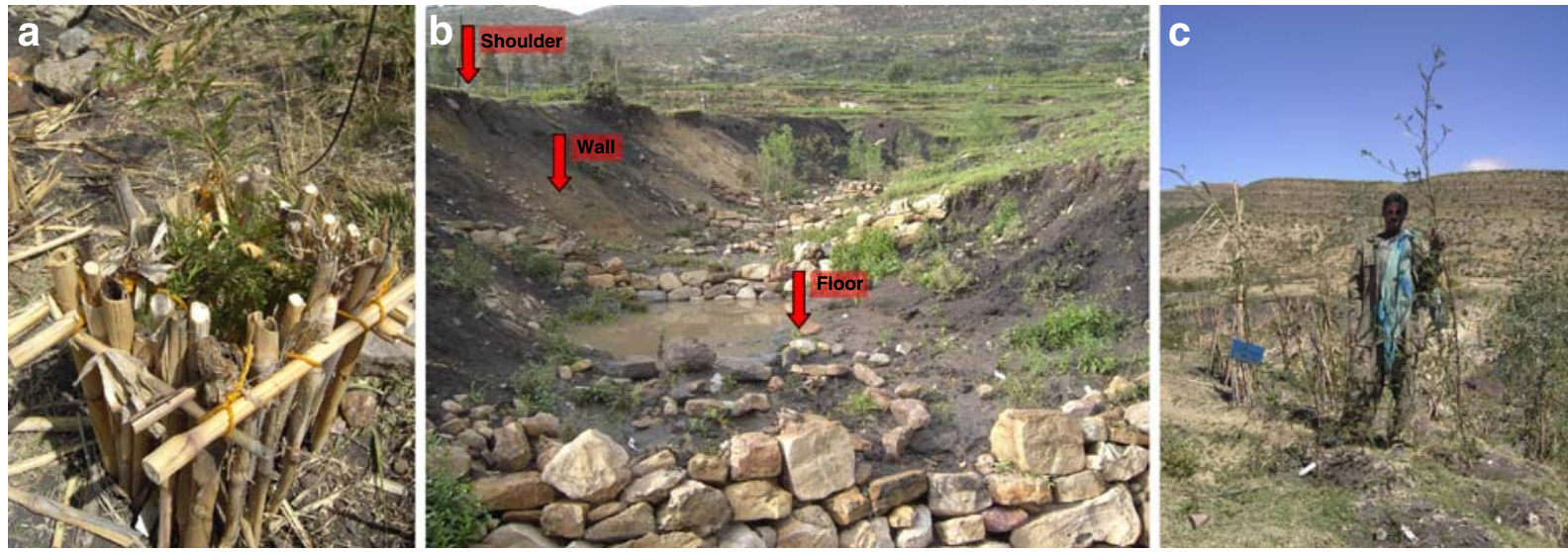

Fig. 3 Illustration of the experiment: a 8 month old $A$. etbaica seedling with shelter; $\mathbf{b}$ indication of gully positions in Adi Worho; $\mathbf{c} S$. sesban seedling towering high above the others, 3 months after planting

land use (including grazing pressure and human disturbance) and upstream gully drainage area (mapped using a Trimble RTK 5800 GPS device) were measured. Two detailed soil profile descriptions were made at every site, followed by soil classification using World Reference Base (IUSS Working Group WRB 2006).

A more detailed sampling strategy was used to collect samples for soil physical and chemical analysis, with samples at two depth intervals (0$15 \mathrm{~cm}$ and $15-30 \mathrm{~cm}$ ) collected on the gully shoulder, wall as well as floor positions, at both sides of the gully (left and right, facing down slope) and at two positions along the main gully axis, resulting in ten soil sampling units or a total of 20 samples per site (see Fig. 2a). These were used for the determination of available phosphorus $\left(\mathrm{P}_{\mathrm{av}}\right)$ in a sodium hydrogen carbonate extract (Olsen's method), carbonate content $\left(\mathrm{CaCO}_{3}\right)$ (titrimetric), texture by dispersion, decantation and sedimentation, Cation Exchange Capacity (CEC) and exchangeable bases following the Silverthiourea method, electrical conductivity $\left(\mathrm{EC}_{\mathrm{w}}\right)$ and $\mathrm{pH}$ in a $\mathrm{H}_{2} \mathrm{O}$ solution, and total carbon $\left(\mathrm{C}_{\text {tot }}\right)$ and nitrogen content $\left(\mathrm{N}_{\text {tot }}\right)$ with the Dumas combustion method using a Solid Carbon Analyser (Vario Max C/ $\mathrm{N}$ apparatus-Elementar Analysensysteme $\mathrm{GmbH}$, Germany). Organic carbon content $\left(\mathrm{C}_{\text {org }}\right)$ was calculated by subtracting the carbon present as $\mathrm{CaCO}_{3}$ from the total carbon content. Kopecky cylinders were used to take samples for soil bulk density determination. Soil water content (SWC) was determined gravimetrically at least once per season, covering the soil sampling units defined above.
Non-destructive repeated measurements of seedling growth response

Seedling survival was assessed weekly. Both disappeared (eroded by the flood or covered by sediment) and visibly dead seedlings were considered as mortality. Plant growth was monitored by recording length (measured along the main plant axis), base diameter $\left(\mathrm{D}_{\text {base }}\right.$ - assessed in two perpendicular directions using a digital calliper), number of stems ( $\mathrm{N}$. stems), number of twigs (N.twigs), crown dimension (crown-measured in two perpendicular directions and calculated as area of an ellipse), presence of flowers and presence of fruit. For a subset of ten leaves per plant, the leaf dimensions (leaf length and width) were measured as well.

These growth characteristics were initially evaluated on a monthly basis, then every 3-6 months, resulting in a total of nine evaluation moments during the course of the experiment (Fig. 4).

\section{Destructive seedling measurements}

With a 1 year interval (in October 2007 and October 2008), a limited number of destructive plant samples (each time 24 seedlings, i.e. four replicates per species per site) was collected. After measurement and removal of the aboveground part, roots were manually excavated. Subsequently, all plant material was divided into leaves, stem + branches and roots, which were first weighed fresh and then oven-dried for at least $24 \mathrm{~h}$ at $70^{\circ} \mathrm{C}$ to obtain dry mass. For a subset of these plants, fresh leaf size was assessed using a Leaf 
Fig. 4 Monitoring scheme in relation to dry and wet periods, with indication of monthly rainfall. Bold and underlined numbers indicate evaluation moments used for Repeated Measures Analysis

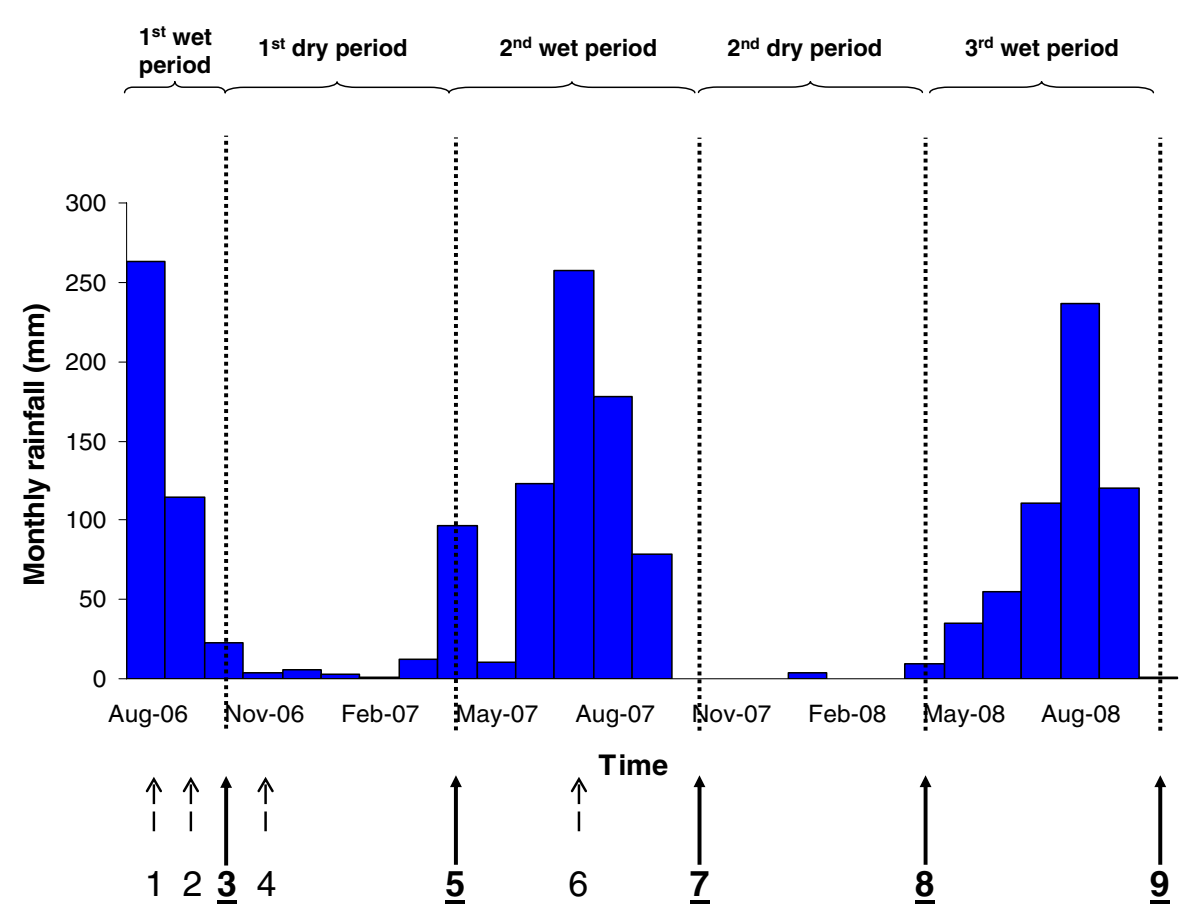

Area Meter (CI-202 Area Meter with Scanman head, logitech. CID, Inc.). Though not included in ANOVA-analyses due to the small number of replicates, these biomass and leaf area assessments were useful for calculation of derived plant growth characteristics.

\section{Derived plant growth characteristics}

A forward linear regression approach was used to derive species-specific allometric relations estimating average individual leaf area $\left(\mathrm{A}_{\mathrm{L}}\right)$ and total aboveground biomass $(\mathrm{BM})$ of all seedlings at all evaluation moments. The following regression formulas were finally most suited:

(a) for leaf area $\left(\mathrm{A}_{\mathrm{L}}, \mathrm{cm}^{2}\right)$ :

\begin{tabular}{lll}
\hline S. sesban: & $\mathrm{A}_{\mathrm{L}}=0.410 \cdot \mathrm{L}_{\mathrm{L}}-23.565$ & $\mathrm{R}^{2}=0.90 ; P<0.001, N=10$ \\
D. angustifolia: & $\mathrm{A}_{\mathrm{L}}=0.006 \cdot \mathrm{L}_{\mathrm{L}} \cdot \mathrm{W}_{\mathrm{L}}$ & $\mathrm{R}^{2}=0.99 ; P<0.001, N=60$
\end{tabular}

with $\mathrm{L}_{\mathrm{L}}=$ leaf length $(\mathrm{mm})$ and $\mathrm{W}_{\mathrm{L}}=$ leaf width $(\mathrm{mm})$.

(b) for aboveground biomass (BM, g):

\begin{tabular}{|c|c|c|c|}
\hline \multirow[t]{2}{*}{ - A. etbaica: } & $\mathrm{BM}=0.664 \cdot \mathrm{D} \cdot \mathrm{L}-6.996$ & for $\mathrm{AK}$ and & \\
\hline & $\mathrm{BM}=0.503 \cdot \mathrm{D} \cdot \mathrm{L}-6.996$ & for AW & $\mathrm{R}^{2}=0.95, P<0.001, N=12$ \\
\hline \multirow[t]{2}{*}{ - S. sesban: } & $\mathrm{BM}=3.532 \cdot\left(\mathrm{D}^{2} \cdot \mathrm{L}\right)^{0.621}$ & for $\mathrm{AK}$ and & \\
\hline & $\mathrm{BM}=3.532 \cdot\left(\mathrm{D}^{2} \cdot \mathrm{L}\right)^{0.733}$ & for AW & $\mathrm{R}^{2}=0.98, P<0.001, N=12$ \\
\hline D. angustifolia: & $\mathrm{BM}=0.409\left(\mathrm{D}^{2} \cdot \mathrm{L}\right)^{0.980}$ & & $\mathrm{R}^{2}=0.99, P<0.001, N=10$ \\
\hline
\end{tabular}

with $\mathrm{D}=\mathrm{D}_{\text {base }}(\mathrm{cm})$ and $\mathrm{L}=$ length $(\mathrm{cm})$.

Absolute as well as relative growth rates for length $\left(\mathrm{AGR}_{\mathrm{L}}, \mathrm{mm}\right.$ day $^{-1}$ and $\mathrm{RGR}_{\mathrm{L}}, \mathrm{mm} \mathrm{cm}{ }^{-1} \mathrm{day}^{-1}$, respectively), $D_{\text {base }}\left(\mathrm{AGR}_{\mathrm{D}}, \mu \mathrm{m}\right.$ day $^{-1}$ and $\mathrm{RGR}_{\mathrm{D}}$, $\mu \mathrm{m} \mathrm{mm}{ }^{-1}$ day $^{-1}$ ) as well as biomass $\left(\mathrm{AGR}_{\mathrm{W}}, \mathrm{g}_{\text {day }}{ }^{-1}\right.$ and $\mathrm{RGR}_{\mathrm{W}}, \mathrm{g} \mathrm{g}^{-1}$ day $^{-1}$ ) were calculated for every period between two evaluation moments, with the following equations used in the classical approach (Grime and Hunt 1975):

$A G R x=\frac{X 2-X 1}{t 2-t 1}$ 
and

$R G R x=\frac{\ln (X 2)-\ln (X 1)}{t 2-t 1}$

where $X_{1}$ and $X_{2}$ are the values of plant length, $D_{\text {base }}$ or biomass at times $t_{1}$ and $t_{2}$.

Furthermore, the following seedling traits were assessed: root-shoot ratio (R:S; $\mathrm{g} \mathrm{g}^{-1}$ ); leaf, stem and root dry matter content (LDMC, SDMC, RDMC; dry mass per unit fresh leaf, stem or root mass; \%); and leaf, stem and root mass fractions (LMF, SMF, RMF; dry leaf, stem or root mass per unit dry plant mass; $\mathrm{g} \mathrm{g}^{-1}$ ).

\section{Statistical analyses}

Analysis of variance (ANOVA) was used to assess effects of site and treatments on plant growth performance. Kolmogorov-Smirnov and Levene's tests were used to test normality and to check for homogeneity of variances, respectively. If required, variables were transformed.

For those plant variables repeatedly assessed throughout the course of the experiment, a Repeated Measures Analysis (RMA) was performed. This ANOVA procedure analyzes groups of related dependent variables that represent measurements of the same attribute at different times, by defining a withinsubject factor (Time). The latter is assigned a number of factor levels corresponding to the number of evaluations taken into account for the studied attribute (maximum nine). In most cases, five fixed evaluations, each with an interval of 6 months between two subsequent evaluations, were selected. Although the main rainy season generally is concentrated between mid-June and mid-September (Nyssen et al. 2008), these 6-month intervals (October-April-October) more or less corresponded with a dominantly 'dry' or 'wet' period, enabling also differentiation of climate-related effects (see Fig. 4 for an overview). This procedure made it possible to assess overall trends and effects, as well as to elaborate upon changes or effects in any specific time period. Bonferroni's test was applied for post-hoc analysis.

Kaplan-Meier survival analysis was used to estimate plant survival rate, but also to assess rates of fruiting and flowering at each point in time, and treatment effects thereupon.
Environmental variables, soil physical and chemical characteristics as well as soil water content (further referred to as soil characteristics) were expected to be significantly different between both sites and therefore to play a major role in plant growth performance. In that perspective, both a Principal Components Analysis (PCA) (Kent and Coker 1996) and multivariate analysis of variance with soil characteristics as dependent variables were used to reveal spatial variability in soil conditions. In addition, given its dynamic nature, differences in SWC between both watering treatment levels were evaluated during the dry period.

Non-parametric statistics (Siegel and Castellan 1988) were used where needed.

Statistical analyses were performed using SPSS 15.0 (SPSS Inc., Chicago, IL) and PCord 4.0 (McCune and Mefford 1999).

\section{Results}

Species-specific plant traits, survival and growth

Although trends differed between both sites (see next paragraph), Sesbania had the lowest overall mortality (18\%), whereas mortality of Acacia (30\%) and Dodonaea (32\%) were similar (Fig. 5). Mortality rate for Dodonaea was especially high in the first weeks after planting (August-September '06). Later, two more mortality peaks were experienced, during the summer rains of ' 07 and '08. On the other hand, except for a small mortality peak at the onset of the experiment, both Sesbania and Acacia remained relatively unaffected during the first year, but later experienced several moderate mortality peaks (see Fig. 5).

Tables 2 and 3 provide an overview of speciesspecific growth characteristics. Differences in growth between species were very pronounced, with Sesbania clearly being the fastest developing, as reflected in all plant growth characteristics. In the first 26 months, dry mass increased at an average rate of $118 \mathrm{~g} \mathrm{month}{ }^{-1}$ for Sesbania as opposed to $1.2 \mathrm{~g} \mathrm{month}^{-1}$ and $3.1 \mathrm{~g} \mathrm{month}^{-1}$ for Acacia and Dodonaea, respectively (Table 2). Plant mass fraction values indicated how Sesbania invested relatively less in leaf biomass and more in aboveground woody biomass, 
Fig. 5 Cumulative survival rate for the three species.

Black diamonds: A. etbaica, Grey triangles: D. angustifolia, White squares:

S. sesban

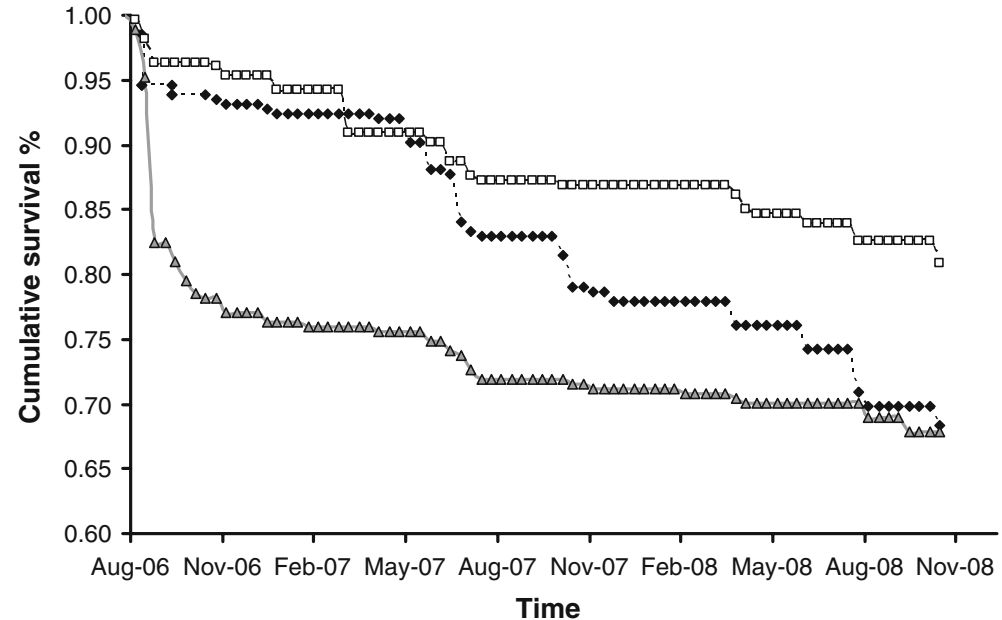

whereas Acacia invested most of its resources in root biomass.

The three species differed not only in growth, but also in speed of flowering, fruiting and regeneration, with Sesbania clearly being fastest and most prolific: within 2 months after planting 14\% of all Sesbania seedlings in AW were flowering, followed soon by AK (28\% after 3 months). Seedlings bore fruit for the first time after less than 8 months (87\% in AW, 51\% in AK). Soon, new seedlings spontaneously established in AW (not in AK), with more than 1,850 seedlings observed (average of two seedlings per $\mathrm{m}^{2}$ ) immediately after the rainy season of 2007 (data not shown). Nevertheless, only $25 \%$ of those new seedlings survived the 2nd dry period. For Dodonaea, it took until the 3rd wet period before significant numbers of seedlings were flowering or fruiting. For Acacia seedlings flowering or fruiting rarely took place within these first few years, with only a few observations in AW, first noticed during the 2nd rainy season.

In addition to the regularly measured plant characteristics, it was also observed how both Acacia and Sesbania seedlings were capable to re-sprout after being cut at the base. Acacia seedlings also resprouted after being completely buried by sediment deposits $(2-10 \mathrm{~cm})$ on the floor.

Finally, the three species differed also in the way they responded to the different treatments attributed.

Table 2 Relevant biomass characteristics (mean \pm standard deviation over repeated measurements) with representation of the nonparametric test results indicating species differences

\begin{tabular}{|c|c|c|c|c|c|}
\hline Variable (unit) & Acacia & Sesbania & Dodonaea & $\chi^{2}$ & $\mathrm{P}$-value \\
\hline RGRW ( $\mathrm{g} \mathrm{g}^{-1}$ day $^{-1}$ ) & $0.003 \pm 0.007^{\mathrm{a}}$ & $0.012 \pm 0.004^{\mathrm{b}}$ & $0.005 \pm 0.008^{\mathrm{a}}$ & 16.595 & $0.000 * *$ \\
\hline AGRW (g month ${ }^{-1}$ ) & $1.18 \pm 1.79^{\mathrm{a}}$ & $118.05 \pm 169.17^{\mathrm{b}}$ & $3.09 \pm 4.70^{\mathrm{a}}$ & 14.595 & $0.000 * *$ \\
\hline LDMC (\%) & $49.67 \pm 9.86^{\mathrm{a}}$ & $47.52 \pm 16.86^{\mathrm{ab}}$ & $39.85 \pm 11.53^{\mathrm{b}}$ & 6.857 & $0.032 *$ \\
\hline SDMC (\%) & $54.25 \pm 8.98^{\mathrm{a}}$ & $48.74 \pm 8.04^{\mathrm{b}}$ & $57.69 \pm 6.35^{\mathrm{a}}$ & 14.171 & $0.001 * *$ \\
\hline $\operatorname{LMF}\left(\mathrm{g} \mathrm{g}^{-1}\right)$ & $0.21 \pm 0.07$ & $0.10 \pm 0.06$ & $0.29 \pm 0.09$ & 1.286 & 0.257 \\
\hline $\operatorname{SMF}\left(\mathrm{g} \mathrm{g}^{-1}\right)$ & $0.30 \pm 0.09$ & $0.66 \pm 0.05$ & $0.46 \pm 0.12$ & 0.818 & 0.366 \\
\hline $\operatorname{RMF}\left(\mathrm{g} \mathrm{g}^{-1}\right)$ & $0.50 \pm 0.10$ & $0.21 \pm 0.04$ & $0.25 \pm 0.11$ & 0.333 & 0.564 \\
\hline
\end{tabular}

Values followed by a different character are significantly different from each other at a significance level of 0.05 with WilcoxonMann-Whitney test

$R G R W$ and $A G R W$ relative and absolute growth rate biomass, respectively; $L D M C, S D M C$ leaf or stem + branch dry matter content, defined as dry mass per unit fresh leaf or stem + branch mass, respectively; $L M F, S M F$ and $R M F$ leaf, stem + branch and root mass fraction, respectively, defined as dry mass per unit dry plant mass

$* P<0.05 ; * * P<0.01$ (Kruskall-Wallis) 


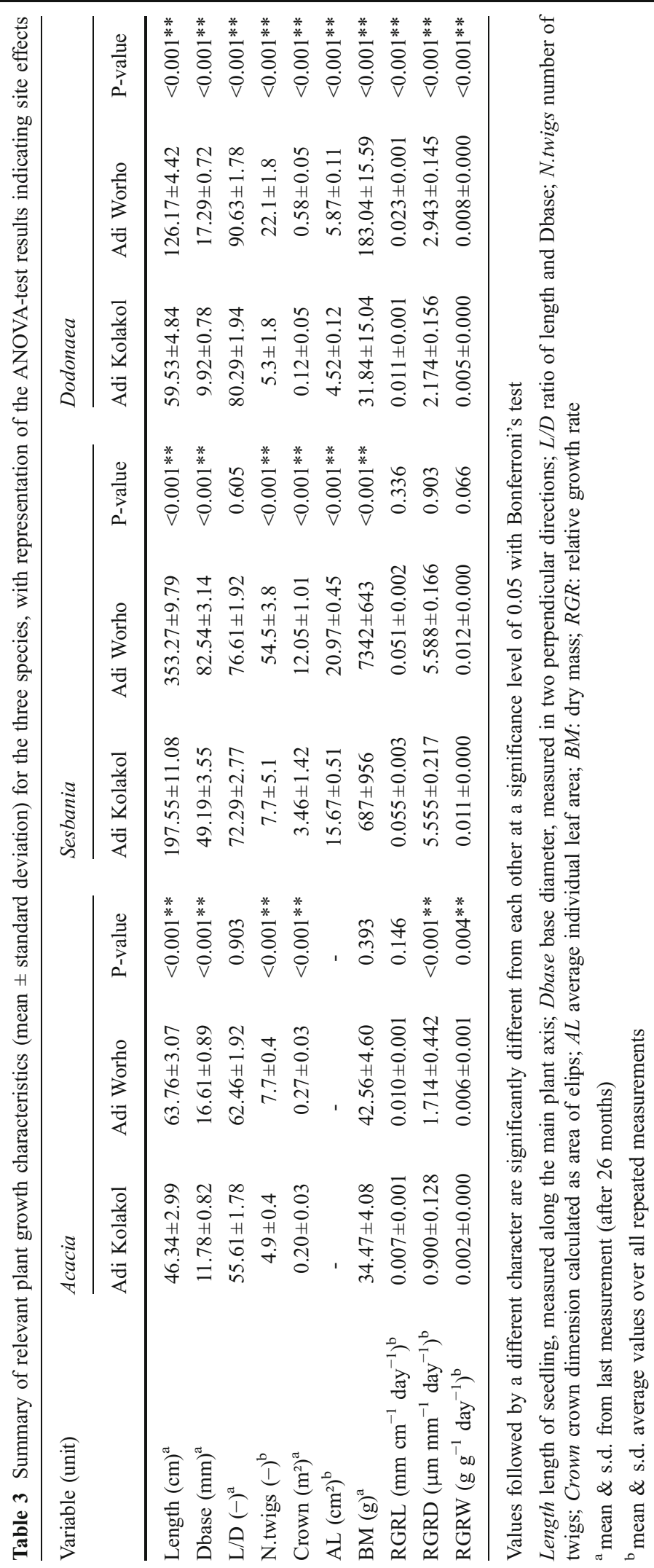


Further analyses were therefore performed separately per species.

Differences in site conditions and their effect on plant growth performance

The results of the PCA and manova (Table 1) revealed that almost all soil characteristics were significantly different between both sites, with a higher water and nutrient availability in the Vertisol area of AW when compared to the sandy colluvium in AK. PCA also revealed a clear clustering of soil units per site (Fig. 6). Variance could not be explained by a limited number of soil characteristics, but is determined by a wide set of (intercorrelated) variables including exchangeable bases, texture, stoniness, carbon content and SWC. Although SWC in AK is remarkably lower for seedlings under low $(0.048 \pm$ $\left.0.010 \mathrm{~g} \mathrm{~g}^{-1}\right)$ than for those under high watering $\left(0.093 \pm 0.013 \mathrm{~g} \mathrm{~g}^{-1}\right)$, this could not be proven statistically. In AW, no effect of watering treatment on SWC was observed. The significant site effect mentioned above $(68 \%$ and $48 \%$ wetter in AW than in AK during dry and wet periods, respectively) appeared therefore to be relatively more determining than the effect of the watering treatment.

Seedling mortality rate after 26 months was $22.5 \%$ in $\mathrm{AW}$ and $30.9 \%$ in $\mathrm{AK}$. In AK, mortality was significantly higher for Dodonaea (39\%) than for Acacia (26\%) and Sesbania (27\%), whereas in AW, mortality was highest for Acacia (35\%), followed by Dodonaea (25\%), and with a remarkably lower mortality for Sesbania (9\%). Despite these relatively small differences in mortality, differences in plant

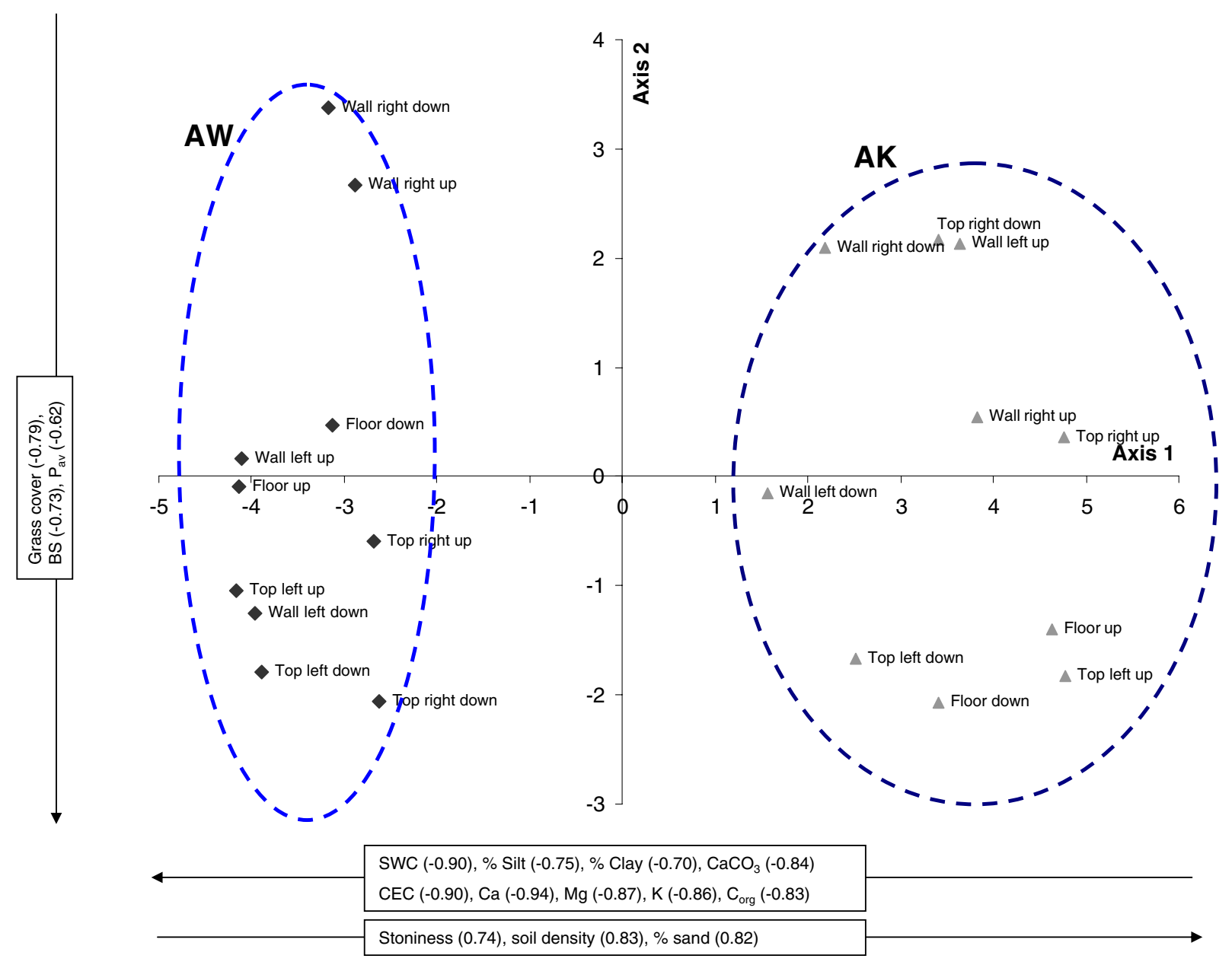

Fig. 6 PCA results based on soil characteristics. Black diamonds: sampling units in AW, grey triangles: sampling units in AK 
growth performance between both sites were very pronounced for all species, with an overall significantly better performance in the Vertisol area of AW (Table 3 and Fig. 7). Presence of fruit and flowers was also significantly higher in AW than in AK for all species.

In Fig. 7, the bigger the differences in curve slope between the different treatment levels for a certain species are, the more important the considered treatment effect was in that specific time interval. Though depending on the species and plant characteristic considered, the main differentiation between both growth sites generally took place during the 1st year after planting, after which the established trend was either maintained or decreased gradually.

An exploratory multi-factor analysis including Site, Position, Shelter and Watering as factors (details not shown), revealed how Site not only determined the main differentiation in plant growth characteristics, but also frequently interacted with other treatments, especially with Position. This could explain why certain treatment effects were different for both
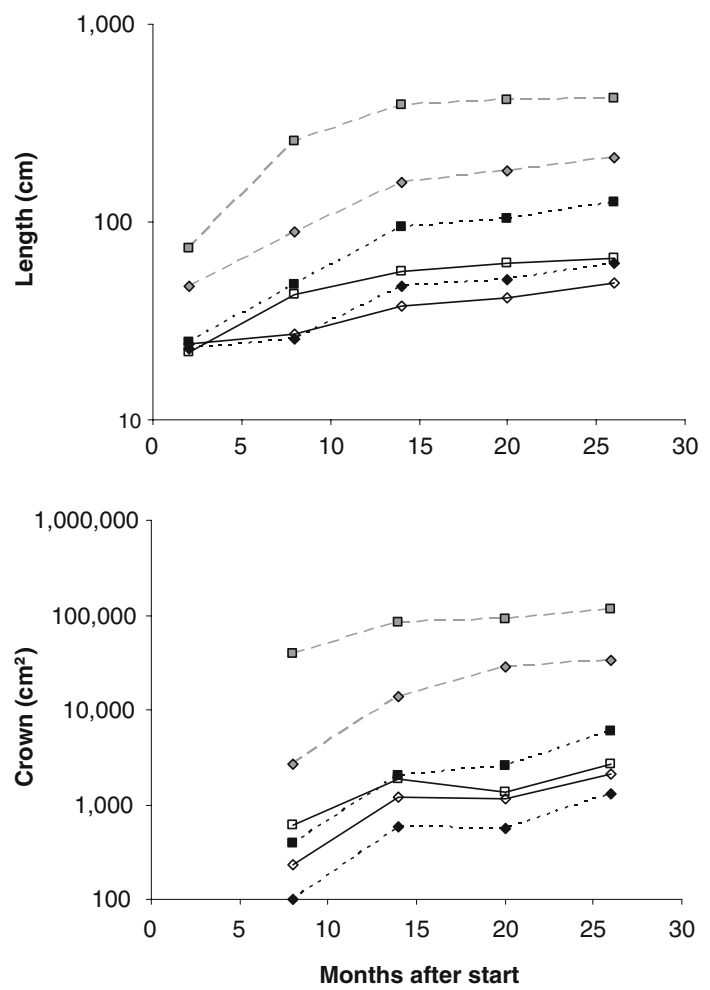

sites. In the remainder of this article, evaluation of treatment effects is performed separately for each site.

Treatment effects on plant mortality and regeneration

At both sites, mortality for Acacia and Dodonaea was highest on the gully floor: of all dead Acacia seedlings, $72 \%$ (in $\mathrm{AK}$ ) and 44\% (in $\mathrm{AW}$ ) were found on the floor. For Dodonaea this ratio reached 57\% and $94 \%$, in AK and AW respectively (data not shown). For Sesbania the same effect was only found in AW, where $75 \%$ of all mortality took place on the floor. Sheltering significantly increased the survival rate at both sites and in all gully positions. This effect was strongest for Acacia seedlings, for which $67 \%$ (in AK) and 79\% (in AW) of all dead seedlings had no shelter. For Dodonaea a similar trend was observed, whereas Sesbania was not significantly affected. Watering treatment only affected Sesbania mortality in AK, with a significantly lower mortality for those seedlings receiving more water.
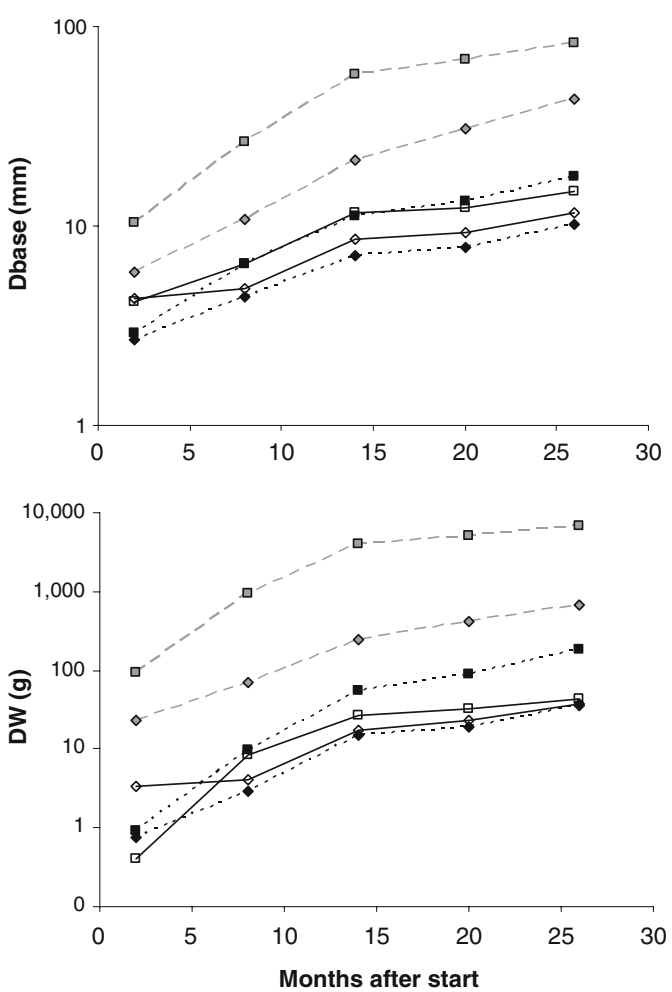

Fig. 7 Site effect on species performance through time. White symbols (full line): A. etbaica; grey symbols (interrupted line): S. sesban; black symbols (dotted line): D. angustifolia. Diamonds: Adi Kolakol; squares: Adi Worho 
Sesbania seedlings on the floor bore significantly faster and more fruit than those on shoulder and wall positions. Sheltering also had a significant influence on flowering, with a slightly higher flowering incidence for unsheltered Sesbania seedlings as compared to sheltered ones. Even more, flowering time distribution was affected by sheltering, with unsheltered seedlings flowering faster (data not shown).

Time and treatment effects on plant growth

Generally, five time levels (3, 5, 7, 8 \& 9; see Fig. 4) were taken into consideration for RMA procedures (output in Tables 4 and 5). Exceptions were the variables N.twigs and crown, as a result of measurement limitations at certain moments. Unless differently stated, mean and standard deviation values mentioned are those of the last evaluation (after 26 months), while P-values are average values over all measurement moments included in the RMA. Representative growth graphs indicating time and treatment effects are shown in Fig. 8.

\section{Time effects}

Time levels correspond with evaluation moments, being transitions from a dominantly wet to a dry period or vice versa (Fig. 4). For all species, nearly all growth variables were affected by the within-subject factor Time (Table 4), indicating a significant change. In most cases, within-subject contrasts (not shown) revealed that these changes took place between all Time levels, demonstrating a change that was not temporarily or interrupted, but rather constant. Nevertheless, changes did not necessarily take place at a continuous rate: in Figs. 7 and 8, different slopes between different evaluation moments indicate dissimilar rates of change. For variables such as length, $\mathrm{D}_{\text {base }}$, BM and N.twigs, changes corresponded with an increase or growth, whereas average values of crown or individual leaf size often fluctuated, following an increasing trend during wetter and a decreasing one during dry periods. Absolute and relative growth rates for Acacia and Dodonaea were also characterized by such fluctuating behavior (with often higher rates during wet periods), although the main trend of all RGR's for the three species by and large was a gradual decrease through time.
Time effects significantly interacted with one or more between-subject factors (Position, Shelter and/or Watering) (Table 4), although within-subject contrasts (not shown) indicated that these Time $\times$ Factor interactions did not hold between all Time levels. Similarly, between-subject factor effects on growth variables were generally not significant between all Time levels. These observations indicate that changes over time were different dependent on the level of certain interacting factors taken into consideration, and/or that between-subject factor effects were timedependent. For most plant characteristics, effects mentioned below were generally strongest during the $1^{\text {st }}$ dry season or at least during the 1 st year after planting (Fig. 8).

Growth responses in Adi Kolakol

\section{Gully position effects}

Gully position affected plant characteristics of all species, with the exact responses being speciesdependent. Both for Acacia and Dodonaea, seedling performance was best on the gully shoulder, as evidenced by a significantly affected Length, $\mathrm{D}_{\text {base, }}$ L/D, N.twigs and Crown for Acacia, and $\mathrm{D}_{\text {base, }} \mathrm{L} / \mathrm{D}$, Crown, $\mathrm{RGR}_{\mathrm{D}}$ and $\mathrm{RGR}_{\mathrm{W}}$ for Dodonaea. For Sesbania, performance was least on the wall and more or less similar on shoulder or floor, depending on the plant characteristic considered.

\section{Sheltering effects}

Responses to sheltering were most pronounced for Acacia, with a significantly higher length, $\mathrm{RGR}_{\mathrm{L}}$ and $\mathrm{L} / \mathrm{D}$, and a significantly lower $\mathrm{D}_{\text {base }}, \mathrm{RGR}_{\mathrm{D}}$ and $\mathrm{N}$. twigs for sheltered seedlings. Dodonaea seedlings were affected in the same way, but only for length, $\mathrm{RGR}_{\mathrm{L}}$ and L/D. Sesbania was least affected by sheltering, with only a slightly lower $\mathrm{A}_{\mathrm{L}}$ and a higher length and $\mathrm{RGR}_{\mathrm{L}}$ for sheltered seedlings.

\section{Watering effects}

The only statistically significant effect of the watering treatments was found for Dodonaea, which had a higher L/D for those seedlings receiving more water. Any other notable effect was absent, although Watering sometimes interacted with other factors. 
Table 4 P-values demonstrating effects of position, shelter, watering and time on plant growth variables at both study sites

\begin{tabular}{|c|c|c|c|c|c|c|c|c|c|}
\hline Source of variation & Length & Dbase & $\mathrm{L} / \mathrm{D}$ & N.twigs & Crown & $\mathrm{BM}$ & RGRL & RGRD & RGRW \\
\hline
\end{tabular}

\section{A. Adi Kolakol}

\section{Acacia etbaica}

Within-subject effects

$\begin{array}{lrrrrrrrrr}\text { Time } & <\mathbf{0 . 0 0 1} & 0.065 & <\mathbf{0 . 0 0 1} & <\mathbf{0 . 0 0 1} & <\mathbf{0 . 0 0 1} & <\mathbf{0 . 0 0 1} & <\mathbf{0 . 0 0 1} & <\mathbf{0 . 0 0 1} & <\mathbf{0 . 0 0 1} \\ \text { Time } \times \text { Position } & \mathbf{0 . 0 3 6} & 0.126 & 0.511 & 0.147 & \mathbf{0 . 0 0 6} & 0.963 & \mathbf{0 . 0 0 4} & 0.339 & 0.570 \\ \text { Time } \times \text { Shelter } & <\mathbf{0 . 0 0 1} & <\mathbf{0 . 0 0 1} & <\mathbf{0 . 0 0 1} & \mathbf{0 . 0 3 6} & \mathbf{0 . 0 0 1} & 0.443 & \mathbf{0 . 0 3 3} & 0.685 & 0.990 \\ \text { Time } \times \text { Watering } & 0.595 & 0.076 & 0.499 & \mathbf{0 . 0 0 1} & 0.132 & 0.215 & 0.546 & 0.143 & 0.589 \\ \text { Between subject effects } & & & & & & & & & \\ \text { Position } & \mathbf{0 . 0 1 7} & \mathbf{0 . 0 0 1} & \mathbf{0 . 2 3 3} & \mathbf{0 . 0 1 0} & \mathbf{0 . 0 0 1} & 0.499 & 0.575 & 0.190 & 0.516 \\ \text { Shelter } & \mathbf{0 . 0 3 2} & <\mathbf{0 . 0 0 1} & <\mathbf{0 . 0 0 1} & \mathbf{0 . 0 0 5} & 0.283 & 0.343 & \mathbf{0 . 0 0 3} & \mathbf{0 . 0 3 3} & 0.530 \\ \text { Watering } & 0.908 & 0.079 & 0.086 & 0.522 & 0.170 & 0.665 & 0.556 & 0.286 & 0.459 \\ \text { Position } \times \text { Shelter } & 0.098 & 0.066 & 0.225 & 0.055 & \mathbf{0 . 0 1 6} & 0.790 & 0.829 & 0.180 & 0.784 \\ \text { Position } \times \text { Watering } & 0.163 & 0.502 & 0.556 & \mathbf{0 . 0 2 2} & \mathbf{0 . 0 0 7} & 0.094 & \mathbf{0 . 0 4 4} & 0.447 & 0.060 \\ \text { Shelter } \times \text { Watering } & 0.515 & 0.363 & 0.908 & 0.494 & 0.720 & 0.439 & \mathbf{0 . 0 2 1} & \mathbf{0 . 0 4 3} & 0.669\end{array}$

\section{Sesbania sesban}

Within-subject effects

Time

Length Dbase

Time $\times$ Position

0.974

0.711

0.342

0.711

$<0.001<0.001$

$<0.001$

$\mathbf{0 . 0 0 2}$

0.599

0.013

0.004

$<0.001$

BM

RGRI

RGRD

RGRW

Time $\times$ Shelter

$<0.001$

0.842

$0.153 \quad 0.079$

0.001

0.067

$<0.001$

$<0.001$

$<0.001$

$<0.001$

Time $\times$ Watering

0.178

0.442

$0.545 \quad 0.859$

0.102

0.054

0.007

0.155

0.528

0.738

Between subject effects

Position

0.465

0.008

$\mathbf{0 . 0 2 3} 0.077$

0.014

0.345

0.002

0.257

0.430

0.294

Shelter

0.241

0.636

$\mathbf{0 . 0 3 0} 0.098$

0.831

$0.308 \quad 0.322$

0.510

0.353

0.608

Watering

0.886

0.414

$0.092 \quad 0.530$

0.410

0.003

Position $\times$ Shelter

0.703

0.661

$0.735 \quad 0.882$

0.968

0.547

0.244

0.134

0.021

0.016

Position $\times$ Watering

0.202

0.710

$0.219 \quad 0.852$

0.298

0.805

0.168

0.002

0.153

0.018

Shelter $\times$ Watering

0.165

0.648

$0.154 \quad 0.986$

0.623

0.448

0.167

0.210

0.830

0.687

0.172

0.575

0.588

Dodonaea angustifolia

Within-subject effects

Time

Length Dba

L/D N.twigs

Crown LA BM

0.020

0.011

0.087

0.053

0.443

0.985

0.693

Time $\times$ Position

0.018

0.002

$<0.001$

0.360

0.144

0.088

$<0.001$

$<0.001$

$<0.001<0.001$

RGRL

RGRD

RGRW

Time $\times$ Shelter

$<0.001$

0.75

$<0.001$

0.107

0.293

0.57

$<0.001$

$<\mathbf{0 . 0 0 1}$

$<0.001$

Time $\times$ Watering

0.895

0.382

0.171

0.432

0.036

$\mathbf{0 . 0 0 3} 0.699$

0.538

0.668

0.587

Between subject effects

Position

0.374

0.001

$0.018 \quad 0.044$

0.082

0.761

0.003

0.04

0.533

0.858

Shelter

0.039

0.146

$<0.001 \quad 0.535$

0.335

0.905

0.727

$<0.001$

0.544

0.866

0.969

0.178

$\mathbf{0 . 0 4 0} 0.698$

0.984

0.800

0.436

0.964

0.432

0.374

0.487

0.708

0.222

0.664

0.476

0.490

0.589

0.099

0.219

0.291

$\mathbf{0 . 0 4 7}$

0.429

$\mathbf{0 . 0 3 8} 0.370$

0.231

0.243

0.478

0.001

0.874

0.585

0.751

0.312

$\mathbf{0 . 0 0 5} 0.807$

0.914

$0.769 \quad 0.578$

0.174

0.401

0.068

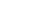


Table 4 (continued)

\begin{tabular}{|c|c|c|c|c|c|c|c|c|c|c|}
\hline Source of variation & Length & Dbase & $\mathrm{L} / \mathrm{D}$ & N.twigs & Crown & $\mathrm{BM}$ & RGRL & RGRD & RGRW & \\
\hline \multicolumn{11}{|l|}{ B. Adi Worho } \\
\hline \multicolumn{11}{|l|}{ Acacia etbaica } \\
\hline \multicolumn{11}{|l|}{ Within-subject effects } \\
\hline Time & 0.171 & 0.001 & $<0.001$ & $<0.001$ & $<0.001$ & 0.001 & $<0.001$ & $<0.001$ & 0.003 & \\
\hline Time $\times$ Position & 0.004 & 0.020 & 0.008 & 0.366 & 0.302 & 0.457 & 0.033 & 0.849 & 0.999 & \\
\hline Time $\times$ Shelter & 0.005 & $<0.001$ & $<0.001$ & 0.064 & 0.281 & 0.945 & $<0.001$ & 0.036 & 0.548 & \\
\hline Time $\times$ Watering & 0.458 & 0.624 & 0.217 & 0.275 & 0.760 & 0.533 & 0.414 & 0.826 & 0.097 & \\
\hline \multicolumn{11}{|l|}{ Between subject effects } \\
\hline Position & 0.010 & 0.111 & 0.013 & 0.216 & 0.053 & 0.002 & 0.019 & 0.031 & 0.382 & \\
\hline Shelter & 0.590 & $<0.001$ & $<0.001$ & $<0.001$ & $<0.001$ & 0.490 & 0.973 & $<0.001$ & 0.091 & \\
\hline Watering & 0.276 & 0.811 & 0.471 & 0.611 & 0.371 & 0.535 & 0.242 & 0.217 & 0.077 & \\
\hline Position $\times$ Shelter & 0.574 & 0.310 & 0.253 & 0.487 & 0.465 & 0.254 & 0.849 & 0.775 & 0.655 & \\
\hline Position $\times$ Watering & 0.946 & 0.230 & 0.916 & 0.273 & 0.687 & 0.438 & 0.559 & 0.336 & 0.318 & \\
\hline Shelter $\times$ Watering & 0.166 & 0.606 & 0.947 & 0.904 & 0.368 & 0.577 & 0.277 & 0.391 & 0.631 & \\
\hline \multicolumn{11}{|l|}{ Sesbania sesban } \\
\hline & Length & Dbase & $\mathbf{L} / \mathbf{D}$ & N.twigs & Crown & LA & BM & RGRL & RGRD & RGRW \\
\hline \multicolumn{11}{|l|}{ Within-subject effects } \\
\hline Time & $<0.001$ & 0.016 & $<0.001$ & $<0.001$ & $<0.001$ & $<0.001$ & $<0.001$ & $<0.001$ & $<0.001$ & $<0.001$ \\
\hline Time $\times$ Position & $<0.001$ & $<0.001$ & 0.232 & $<0.001$ & $<0.001$ & 0.027 & $<0.001$ & $<0.001$ & $<0.001$ & $<0.001$ \\
\hline Time $\times$ Shelter & 0.759 & 0.600 & 0.021 & 0.050 & 0.570 & $<0.001$ & 0.591 & 0.056 & 0.078 & 0.230 \\
\hline Time $\times$ Watering & 0.886 & 0.422 & 0.862 & 0.245 & 0.083 & 0.033 & 0.847 & 0.288 & 0.732 & 0.490 \\
\hline \multicolumn{11}{|l|}{ Between subject effects } \\
\hline Position & $<0.001$ & $<0.001$ & 0.038 & $<0.001$ & $<0.001$ & 0.001 & $<0.001$ & 0.001 & $<0.001$ & $<0.001$ \\
\hline Shelter & 0.275 & 0.887 & 0.017 & 0.274 & 0.935 & 0.001 & 0.960 & 0.183 & 0.253 & 0.878 \\
\hline Watering & 0.999 & 0.405 & 0.584 & 0.694 & 0.475 & 0.006 & 0.871 & 0.801 & 0.649 & 0.923 \\
\hline Position $\times$ Shelter & 0.411 & 0.987 & 0.070 & 0.785 & 0.349 & 0.761 & 0.793 & 0.282 & 0.722 & 0.359 \\
\hline Position $\times$ Watering & 0.154 & 0.635 & 0.081 & 0.569 & 0.239 & 0.080 & 0.593 & 0.208 & 0.637 & 0.923 \\
\hline Shelter $\times$ Watering & 0.559 & 0.866 & 0.894 & 0.887 & 0.236 & 0.342 & 0.495 & 0.208 & 0.940 & 0.736 \\
\hline \multicolumn{11}{|l|}{ Dodonaea angustifolia } \\
\hline & Length & Dbase & $\mathbf{L} / \mathbf{D}$ & N.twigs & Crown & $\mathbf{L A}$ & BM & RGRL & RGRD & RGRW \\
\hline \multicolumn{11}{|l|}{ Within-subject effects } \\
\hline Time & $<0.001$ & $<0.001$ & $<0.001$ & $<0.001$ & $<0.001$ & $<0.001$ & $<0.001$ & $<0.001$ & $<0.001$ & $<0.001$ \\
\hline Time $\times$ Position & $<0.001$ & 0.011 & $<0.001$ & 0.246 & 0.023 & 0.586 & 0.090 & 0.118 & 0.145 & 0.784 \\
\hline Time $\times$ Shelter & 0.249 & 0.001 & $<0.001$ & 0.198 & 0.115 & 0.682 & 0.393 & 0.050 & 0.056 & 0.140 \\
\hline Time $\times$ Watering & 0.298 & 0.813 & 0.336 & 0.705 & 0.293 & 0.384 & 0.988 & 0.293 & 0.941 & 0.969 \\
\hline \multicolumn{11}{|c|}{ Between subject effects } \\
\hline Position & 0.006 & 0.083 & 0.001 & 0.296 & 0.031 & 0.840 & 0.260 & $<0.001$ & 0.243 & 0.071 \\
\hline Shelter & 0.180 & 0.001 & $<0.001$ & 0.121 & 0.936 & 0.522 & 0.159 & 0.113 & 0.362 & 0.928 \\
\hline Watering & 0.860 & 0.188 & 0.525 & 0.667 & 0.683 & 0.018 & 0.381 & 0.461 & 0.991 & 0.811 \\
\hline Position $\times$ Shelter & 0.643 & 0.491 & 0.431 & 0.707 & 0.585 & 0.872 & 0.876 & 0.141 & 0.648 & 0.574 \\
\hline Position $\times$ Watering & 0.351 & 0.113 & 0.542 & 0.726 & 0.379 & 0.059 & 0.280 & 0.128 & 0.045 & 0.111 \\
\hline Shelter $\times$ Watering & 0.010 & 0.061 & 0.442 & 0.093 & 0.034 & 0.016 & 0.029 & 0.051 & 0.191 & 0.116 \\
\hline
\end{tabular}

Results were analysed using GLM repeated measures and univariate anova. Bold: $p<0.05$ 


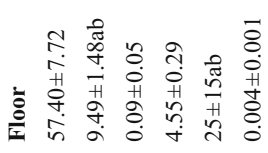

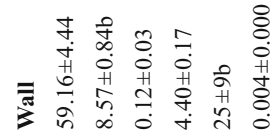

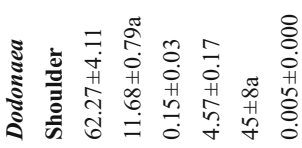

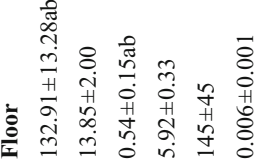

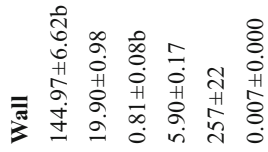

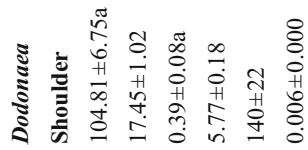

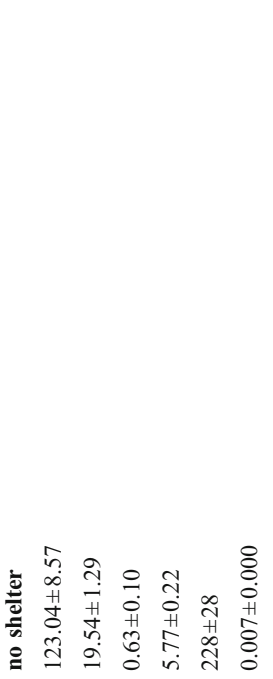

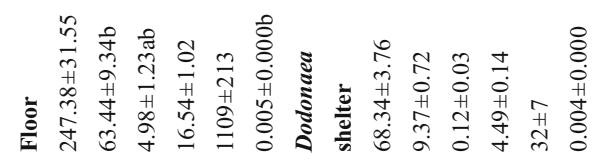

तิ

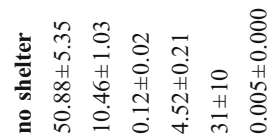

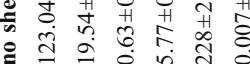

릉

ले

ฮึँ

정

혹

:

อู

के

응

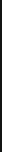

$\frac{\text { a }}{\frac{0}{2}}$

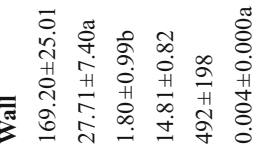

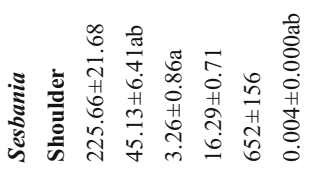

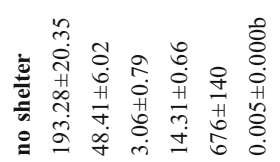

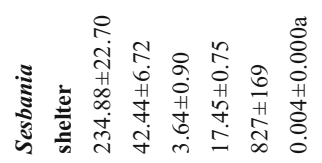

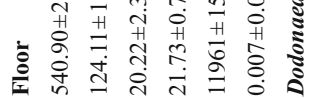

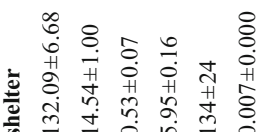

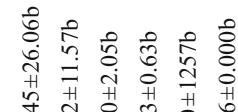

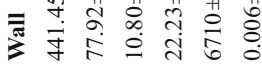

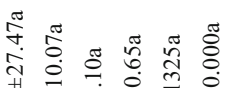

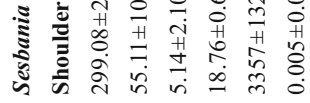

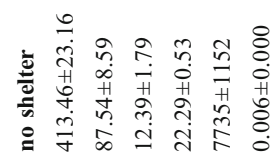

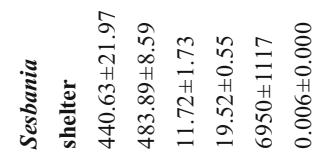

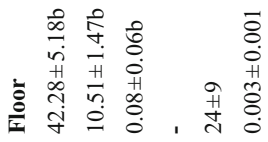

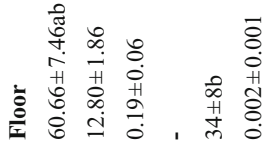

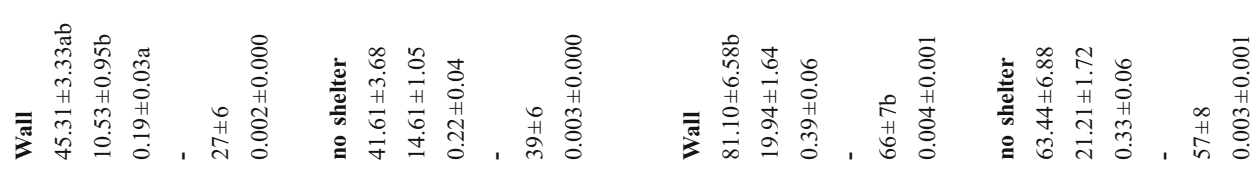

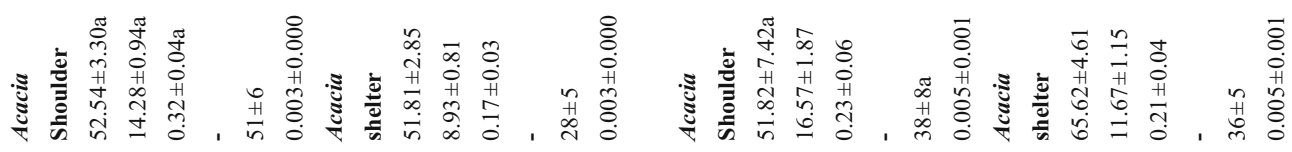

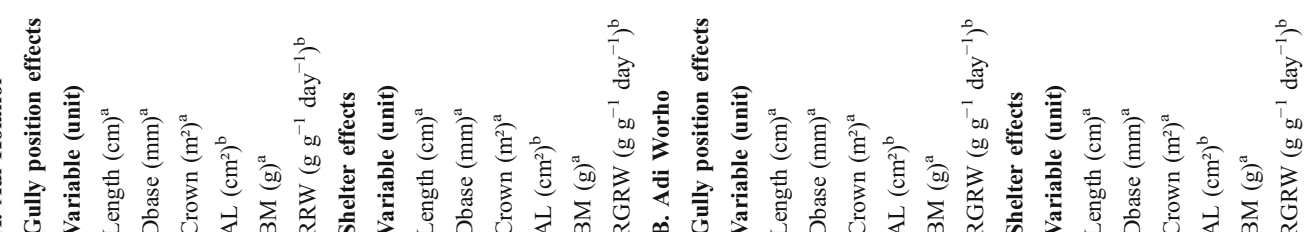


Growth responses in Adi Worho

\section{Gully position effects}

As in AK, responses to gully position were speciesdependent. For all species, growth was generally least on the gully shoulder. This was most evident for Sesbania, with virtually all growth characteristics affected and best performance on the gully floor. Performance of both Acacia and Dodonaea was best on the wall.

\section{Sheltering effects}

For all species, responses to sheltering were very similar to those observed in AK. Again effects were most pronounced for Acacia, with a significantly higher $\mathrm{L} / \mathrm{D}$ and a significantly lower $\mathrm{D}_{\text {base }}, \mathrm{RGR}_{\mathrm{D}}, \mathrm{N}$. twigs and crown for sheltered seedlings. For Dodonaea seedlings, a significantly higher $\mathrm{L} / \mathrm{D}$ and a significantly lower $\mathrm{D}_{\text {base }}$ were observed, whereas Sesbania was least affected, with only a slightly lower $A_{L}$ and a higher $L / D$ for sheltered seedlings.

\section{Watering effects}

The only plant characteristic significantly affected by the watering treatments was $\mathrm{A}_{\mathrm{L}}$, which for both Sesbania and Dodonaea was significantly higher for those seedlings receiving less water.

For more details we refer to Tables 4 and 5, and to Fig. 8.

\section{Discussion}

Trends in plant survival and growth

Post-planting stress together with flooding during the first month after planting resulted in an initial mortality peak for all species, most evidently for Dodonaea (Fig. 5). For Acacia and Dodonaea, such a mortality peak caused by flooding returned every rainy season, although with a gradually reduced impact. In addition, more irregular intermediate peaks were observed, which could be interpreted in different ways. Drought stress might have played a role here, certainly for Sesbania seedlings. As a result of its fast growth and the relatively small within-plot planting distance, part of Sesbania mortality might also have been the result of self-thinning (2nd degree competition). Sesbania also appeared to be susceptible to different pests, reducing vitality. Several as yet unidentified types of scale insects (Coccoidea) and caterpillars (Lepidoptera) were frequently noticed on the branches. Later, rodents (rats, rabbits or squirrels) also ate its bark. Although probably reducing growth and vitality, this did not frequently result in mortality. Besides Sesbania, in AW at least 25 Acacia seedlings suffered seriously from being uprooted at night by unidentified rodents (as observed by the guards), making uprooting the highest cause of mortality of Acacia in AW.

Results demonstrated some pronounced differences in plant growth and biomass allocation between the studied species. However, differences in biomass allocation could not be proven statistically, due to the low number of destructive replicates. Moreover, root biomass was probably underestimated for the extended root network of Sesbania seedlings.

While difficult to generalize, two main trends of time differentiation in growth and effects can be distinguished. First of all, especially for Acacia and Sesbania, between-subject factor effects were usually strongest in the 1st year after planting, during which growth was generally high. Secondly, especially for Acacia and Dodonaea, plant growth and development appeared to be higher during wet rather than during dry periods, a commonly observed tree growth trend in African (semi-)arid areas (Broadhead et al. 2003). This indicates that between-subject factor effects depended for example on the growth development stage or specific weather conditions. It was furthermore observed that RGR declined as plants grew, in accordance with previous observations (Turnbull et al. 2008).

Originally, the shelter treatment was designed to reduce overexposure to sunlight. However, it quickly became clear that sheltering had several other protective advantages, such as the capture of rough plant material (branches, grass) transported by the flood, the physical barrier protection against the flood, and the ability to avoid browsing by rodents if constructed properly. It is important to keep the shelter open at the top, in order not to hinder the growth of the plant itself. Growth response to sheltering was straightforward: for all species, having a shelter resulted in a smaller $D_{\text {base }}$ and a higher $L / D$. This might be 

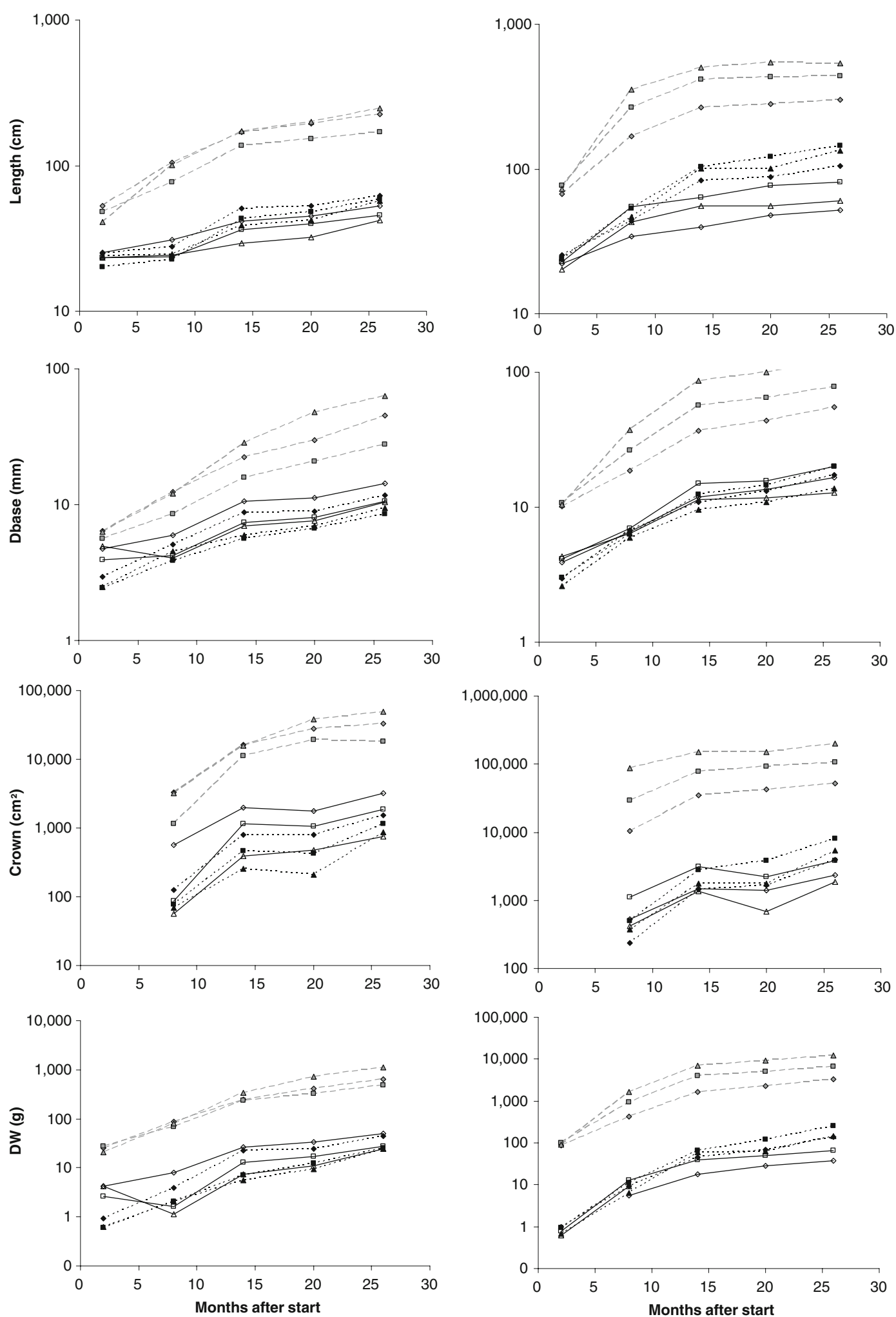

Fig. 8 Effects of gully position on species performance through time. Left: AK, right: AW. White symbols (full line): A. etbaica; grey symbols (interrupted line): S. sesban; black symbols (dotted line): D. angustifolia. Diamonds: shoulder; squares: wall; triangles: floor 
interpreted as a trend in which the plant rushes to grow towards the light and invests relatively more in an increase in height, as was previously also observed for the more commonly used plastic tube shelters (West et al. 1999). On the other hand, this could also be considered as a thigmomorphogenetic response, in which unsheltered seedlings are more exposed to wind disturbance, resulting in a reduced height and thicker stem diameter (Jaffe 1973; Read and Stokes 2006; Reubens et al. 2009). While for Acacia and Dodonaea it often took a few months before the sheltering effects became clear, generally, for Sesbania, these effects gradually decreased through time or sometimes even completely disappeared as a result of their fast growth by which they quickly escaped from the low shelter. Knowing that the important beneficial effects of sheltering are strongest in the initial growth stage, but that biomass development may well be suppressed in the long term, it is suggested to carefully remove (or at least not to reinforce) the shelters once seedlings are firmly fixed in the soil and reached a considerable length.

Although the lack of differentiation in watering treatment during the rainy seasons was expected to be masking effects, no significant watering effects were observed even when only taking dry periods into account. Results from other (albeit unfenced) trials in the same area (Aerts et al. 2007) however indicated a very low survival rate for seedlings which were not given any additional water to overcome the first dry season, even if these were drought-resistant species. The ability to develop deep roots and to access soil moisture is decisive for seedling survival, regardless of species-specific drought tolerance. The absence of effects of watering treatment here, is probably a consequence of (1) too small treatment differentiation, and/or (2) the fact that water availability for seedlings was not only determined by the volume provided during the dry season in our treatments, but by a mixture of factors including soil water holding capacity, gully position, irregular aboveground runoff, and belowground percolation and lateral soil water transfers. In addition, one can expect a gully site to have a higher SWC than the surrounding area because of its topographic position. Given the effort needed to provide water on a regular basis, and the general shortage of water towards the end of the dry season, watering should be kept to the absolute minimum required. This minimum will depend upon the planted species, the climate conditions (with $\mathrm{ET}_{0}$ to be taken into account) and the soil conditions (with higher requirements in dry, sandy soils).

Underlying mechanisms and relative importance of soil and environmental conditions

The underlying mechanisms for both site and position effects may well have been similar. Gully position effects could be a result of differences in sunlight or wind exposure, as well as of differences in flood stress, soil shear stresses or soil characteristics such as water and nutrient availability, which are both siteand position-related. More generally stated, as also observed for watering, the effects of the imposed treatments on plant growth performance were not unequivocal, but depended on the specific growth conditions.

Different groups of environmental characteristics could be distinguished (Table 1): climatic, topographic, or soil physical and chemical characteristics. In addition, soil water content is another, more dynamic soil characteristic, affected by seasonality, environment, as well as by the manual watering treatments. All of these might have influenced plant growth performance in some way. Despite slightly better climatic conditions in Adi Worho (higher mean air temperatures, slightly more rainfall), variation in climate conditions was relatively small, and it is probable that the influence of other soil and environmental characteristics, particularly nutrient and water availability, have been relatively more significant.

Values for these soil characteristics (Table 1) were in line with previous observations in the same area (Descheemaeker et al. 2006; Nyssen et al. 2008). Generally, soil characteristics in Tigray are highly variable, controlled by topography and underlying geological formation (Nyssen et al. 2008). More than $50 \%$ of the soils is shallow, very low in organic matter, extremely deficient in both total nitrogen and available phosphorus, but moderately sufficient in potassium (Beyene et al. 2005).

As for gully position, given the different responses depending on the site and species evaluated, it remains difficult to assess a single explanation for the observed trends. It was hypothesized that in general water and nutrient availability would have been higher on the gully floor, where a lateral flux of water and nutrients is expected. Such a trend could 
have explained why Sesbania performed better on the gully floor. Although this is at least part of the explanation, it could not be incontestably proved in the current setup. More replicates at different sites, in which differences in sunlight or wind exposure, flood stress, or soil shear stresses are also assessed in more detail, would therefore be interesting.

In conclusion, although attention was paid to homogeneity in growth conditions, apart from the imposed treatment factors, at each site additional natural heterogeneity also had an influence on seedling development, complicating interpretation of some results. This is the fate of a field trial under natural conditions, certainly on dynamic and heterogeneous landforms like gullies, as contrasted to strictly controlled laboratory or greenhouse experiments. Nevertheless, in real life plant establishment unavoidably takes place in such a complex scenario, where many abiotic and biotic factors act simultaneously and interactively. Therefore understanding these interactions is often even more important than being able to separate individual effects (GomezAparicio et al. 2008).

In this respect, variability in plant growth performance could be differentiated into three main components: (1) a determinate component expressing the trends and effect of the imposed treatments; (2) a determinate component set by additional (spatial) variability in environmental characteristics; and (3) a random undetermined component (including measurement errors).

Species-specific bottlenecks and recommendations

In our sites, Acacia etbaica performed best on the gully shoulder and wall positions. Developing a taproot (Windey 2007), it could be an interesting species for stabilization of the gully walls. On the shoulder, if managed as a dense shrub, Acacia is suitable for development of a natural fence around vulnerable places where vegetation recovery has to be given a chance. On the other hand, given its robustness and capacity to re-sprout, which was also previously observed (World Agroforestry Centre 2002) and is a well-known characteristic of many Acacia species (Noad and Birnie 1989), it could also be an interesting species for frequently disturbed sites or gully bottoms where sediment is being deposited. As a very common species in the research area, its use to reclaim degraded lands (World Agroforestry Centre 2002) should be uncomplicated. Initial sheltering may well be important to protect the seedlings from uprooting by rodents.

Sesbania sesban above- and belowground development was very fast, even though the research area (about 2,500 $\mathrm{m}$ a.s.1.) is not the species' optimum, i.e. between $200 \mathrm{~m}$ a.s.l. and $500 \mathrm{~m}$ a.s.l. (Noad and Birnie 1989). The observations correspond with its description as a short lifespan shrub species with an initially very fast growth rate gradually decreasing through time (Mekonnen et al. 2006; Mengistu et al. 2002). The fast reproduction is in line with its specification as a prolific seeder, with germination rates of about $80 \%$ (Maundu and Tengnäs 2005). It appears to be a species suited to wall and floor stabilization where its growth is best and its mortality low. Its rapid early growth rate could also be exploited by intercropping it with other slower establishing species for earlier yields. As a coppiceable species (Noad and Birnie 1989) the ability to re-sprout after cutting is not surprising. Coppicing yields useful wood material, with cutting frequencies reported of three to four cuts per year. Similarly, pollarding at young age is probably desirable to stimulate investment in fresh leaf development, and to keep the plant strong and its growth rate high. Maintaining a healthy status is important since Sesbania is susceptible to pests and diseases. Similar problems have been observed in several semi-arid lowland regions of eastern and southern Africa, where the establishment of Sesbania sesban has either failed, or substantial crop losses have been incurred, because of the activities of root-knot nematodes, leaf eating beetles (Mesoplatys ochroptera Stäl), caterpillars (Lepidoptera), weevils (Curculionoidea) as well as several species of bacteria and fungi (Sileshi et al. 2000; World Agroforestry Centre 2002). Despite its interesting characteristics, Sesbania should be used carefully and moderately: it is an exotic species with an invasive behavior (Wagner et al. 1999).

Dodonaea angustifolia had its best development on gully shoulder positions. Although this species is said not to be browsed by cattle (Bekelle-Tesemma 1993), and could hence serve as a natural fence around the gully, browsing (especially by goats and donkeys) was observed in the study area. Its extensive shallow root system makes it useful in soil binding and erosion control (Bekelle-Tesemma 1993; Royal 
Botanic Gardens 2007). Dodonaea is a dominant species in exclosures in the study area, actively and easily regenerating (Mengistu et al. 2005), and with a fairly fast biomass increase.

Experimental limitations, extension and long-term follow-up

Though extensive, this study had its limitations, of which the duration of the experiment and the limited number of species and situations were the most important. Nevertheless, in this study we covered the first 2 years of seedling growth, including three rainy seasons. If seedlings survive this first, most critical stage (Sanchez-Gomez et al. 2008) and establish well, there is a high probability to further develop without major problems. Similarly, species were carefully selected and may have important traits in common with other species, which will therefore belong to an identical functional group. In that context, one could assume A. etbaica and $D$. angustifolia to be representative of a wider set of relatively drought resistant shrub or (evergreen) tree species, whereas $S$. sesban could be a prototype of fast-growing, nutrient-fixing fodder species. Species belonging to one functional group could then be expected to respond in a similar way to treatments. Nevertheless, such similarities cannot be taken for granted without further investigation. As a general principle, attention should be given to fast-growing multipurpose species, including promising species which are currently rarely used.

The treatments for this study were selected taking into account local conditions and an effort- and cost-effective approach. Of course, other treatment strategies are possible, and it would be especially interesting to study the effects of nutrient availability and pocket fertilization in more detail. Furthermore, once rates of plant establishment and growth for specific species and sites are well-understood, it would be interesting to assess economic feasibility.

It is noteworthy that this experiment was designed for multi-disciplinary, long-term follow-up, implying evaluation of other aspects not addressed here. These include assessment of natural vegetation growth, soil strength and root reinforcement, and evolution of gully morphology. Furthermore, in a second experimental phase (since August 2007; Woldekidan, unpublished data), three additional woody species were subjected to a similar experimental evaluation, i.e. Cordia africana Lam., Psidium guajava L. and Faidherbia albida (Delile) A. Chev, all selected through a similar multi-criteria decision approach. Treatments and setup were the same, except for an additional zero-watering treatment, included because of the lack of watering differentiation in the former experiment. Here as well, seedling survival and growth were mainly determined by differences in growth conditions at both sites. Fifteen months after planting, Faidherbia had the lowest overall survival rate (44\%), whereas survival of Cordia and Psidium were similar $(60 \%)$. The surprisingly low survival rate for Faidherbia might at least partly be explained by inconvenient nursery practices (e.g. long length of stay in the nursery, taproot pruning, no hardening), stressing the crucial role of a proper seedling handling (Aerts et al. 2007). Psidium had a significantly lower survival when zero watering was applied. Cordia seedlings performed best on the gully wall, whereas Psidium and Faidherbia were less affected by the gully position. Cordia and Faidherbia responded to sheltering in a similar way as observed in the presented study. Despite the introduction of a zero-watering treatment, watering level rarely affected plant growth.

Towards implementation

Successful examples of gully erosion control using locally available resources or woody vegetation in other (semi-)arid environments, such as South China (Li et al. 2004; Sheng and Liao 1997; Xu et al. 2008), the Sahelian region (Ribolzi et al. 2006; Wardman and Salas 1991) or the Mediterranean region (Arabi 2006; Quinton et al. 2002), prove that there is a good potential for effective implementation of such measures in rural development programs, in a way which can even be economically beneficial in the long term. Nevertheless, failures are common if (1) the objectives and actions of the different actors playing a role in the implementation of such programs are not thoroughly understood (Segers et al. 2008), and (2) measures are not inspected regularly for necessary repair, inappropriate species are selected, or treatment and planting conditions are unsuited. As for the former, planning and implementation of soil and water conservation often suffer from over-ambition, upward accountability and a top-down blanket approach (Segers et al. 2008). 
Above all, keeping out grazing and browsing animals from restoration sites is the most critical trigger for a successful plant establishment (Aerts et al. 2007; Negussie et al. 2008; Nyssen et al. 2008). It is not only a precondition when aiming at effective seedling plantings, but it also allows natural vegetation to recover and hence protect the soil against further erosion.

\section{Conclusions}

Except for a few attempts in for example Burkina Faso, Mali and Algeria (Bourougaa and Monjengue 1989), which often had good results but lacked an appropriate statistical approach, this experiment is one of the first (reported) systematic studies on seedling establishment and plant growth performance in the framework of gully erosion control in African semi-arid areas.

Survival, growth and development of seedlings in gullies strongly depend upon their treatment and the growth conditions under which they are planted. For all species in this study, plant growth performance at any time was significantly $(P<0.01)$ different between both growth sites, with an overall higher survival rate and better performance in the nutrient-rich Vertisol area of Adi Worho.

The exact effects of treatment in terms of gully position, sheltering and watering were mainly determined by the considered species and site. Gully position effects were especially different for Sesbania (which had an overall better performance on the gully floor) when compared to both other species. Sheltering effects were more straightforward, and proved to fulfill an important protective role. Remarkably, the different watering treatments almost did not affect survival or growth performance of any of the examined species. Given the complex interaction of factors determining overall seedling water availability, more highly differentiated watering treatments in a controlled research setup are needed to determine species- and site-specific watering thresholds.

Acknowledgements This paper is an output from a $\mathrm{PhD}$ research project funded by the Flemish Interuniversity Council (VLIR) and the Research Foundation Flanders (FWO). We acknowledge FWO for providing a Trimble RTK 5800 GPS. The cooperation with the MU-IUC programme (Land Project) has been very valuable. Special thanks go to Lies Huys, Goytom Desta, Hagos Woldekidan, Muuz Hadush, Fikur
Dimtsu, Romha Assefa, Agazi Hailay, the field assistants and the tree nursery workers for their contributions during fieldwork, to the inhabitants of Adi Worho and Adi Kolakol for their hospitality and input, to Sean Seery for the grammatical corrections, and to the Forecoman colleagues and the two anonymous reviewers for their constructive comments.

\section{References}

Aerts R, November E, Van Der Borght I, Behailu M, Hermy M, Muys B (2006) Effects of pioneer shrubs on the recruitment of the fleshy-fruited tree Olea europaea ssp cuspidata in Afromontane Savanna. Appl Veg Sci 9:117126

Aerts R, Negussie A, Maes W, November E, Hermy M, Muys B (2007) Restoration of dry Afromontane forest using pioneer shrubs as nurse-plants for Olea europaea ssp cuspidata. Restor Ecol 15:129-138

Aerts R, Nyssen J, Haile M (2009) On the difference between 'exclosures' and 'enclosures' in ecology and the environment. J Arid Environ 73:762-763

Arabi M (2006) Anti-erosive structures on small experimental mountainous basins in an Algerian semi-arid envrironment. Z Geom 50:209-220

Bekelle-Tesemma A (1993) Useful trees and shrubs of Ethiopia. Swedish International Development Authority Regional Soil Conservation Unit, Nairobi

Beyene A, Gibbon D, Haile M (2005) Heterogeneity in land resources and diversity in farming practices in Tigray, Ethiopia. Agric Syst 88:61-74

Boix-Fayos C, Barbera GG, Lopez-Bermudez F, Castillo VM (2007) Effects of check dams, reforestation and land-use changes on river channel morphology: case study of the Rogativa catchment (Murcia, Spain). Geomorphology 91:103-123

Bourougaa L, Monjengue S (1989) Fixation mécanique et biologique des ravines: expérimentation dans la région semi-aride de Beni-Slimane Algerie. Bulletin Réseau Erosion 9:19-29

Broadhead JS, Ong CK, Black CR (2003) Tree phenology and water availability in semi-arid agroforestry systems. For Ecol Manag 180:61-73

Castillo VM, Mosch WM, Garcia CC, Barbera GG, Cano JA, Lopez-Bermudez F (2007) Effectiveness and geomorphological impacts of check dams for soil erosion control in a semiarid Mediterranean catchment: El Cárcavo (Murcia, Spain). Catena 70:416-427

De Baets S, Poesen J, Gyssels G, Knapen A (2006) Effect of grass roots on the erodibility of top soils during concentrated flow. Geomorphology 76:54-67

Descheemaeker K, Nyssen J, Rossi J, Poesen J, Haile M, Raes D, Muys B, Moeyersons J, Deckers S (2006) Sediment deposition and pedogenesis in exclosures in the Tigray Highlands, Ethiopia. Geoderma 132:291-314

Dharani N (2002) Field guide to common trees and shrubs of East Africa. Struik, Cape Town

Fichtl R, Admasu A (1994) Honeybee Flora of Ethiopia. The National Herbarium, Addis Ababa University, Deutscher Entwicklungsdienst (DED). Margraf Verlag, Germany 
Gomez-Aparicio L, Perez-Ramos IM, Mendoza I, Matias L, Quero JL, Castro J, Zamora R, Maranon T (2008) Oak seedling survival and growth along resource gradients in Mediterranean forests: implications for regeneration in current and future environmental scenarios. Oikos 117:1683-1699

Grime JP, Hunt R (1975) Relative growth-rate-Its range and adaptive significance in a local flora. $\mathrm{J}$ Ecol 63:393-422

Gyssels G, Poesen J, Bochet E, Li Y (2005) Impact of plant roots on the resistance of soils to erosion by water-a review. Prog Phys Geogr 29:189-217

Haregeweyn N, Poesen J, Deckers J, Nyssen J, Haile M, Govers G, Verstraeten G, Moeyersons J (2008) Sedimentbound nutrient export from micro-dam catchments in northern Ethiopia. Land Degrad Dev 19:136-152

IUSS Working Group WRB (2006) World reference base for soil resources. World Soil Resources Reports No. 103. FAO, Rome

Jaffe MJ (1973) Thigmomorphogenesis-response of plantgrowth and development to mechanical stimulationwith special reference to Bryonia dioica. Planta 114: $143-157$

Jordano P, Godoy JA (2002) Frugivore-generated seed shadows: a landscape view of demographic and genetic effects. In: Levey DJ, Sylva WR, Galetti M (eds) Seed dispersal and frugivory: ecology, evolution and conservation. $\mathrm{CAB}$ International, Wallingford, pp 305-321

Karambiri H, Ribolzi O, Delhoume JP, Ducloux J, CoudrainRibstein A, Casenave A (2003) Importance of soil surface characteristics on water erosion in a small grazed Sahelian catchment. Hydrol Process 17:1495-1507

Kent M, Coker P (1996) Vegetation description and analysis. A practical approach. Wiley, Chichester

Li Y, Bai LY, Zhang XC, Liu DH (2004) Approaches to controlling concentrated flow erosion in the Loess plateau of China. In: Li Y, Poesen J, Valentin C (eds) Gully erosion under global change. Sichuan Science and Technology, Chengdu, pp 340-348

Maundu P, Tengnäs P (2005) Useful trees and shrubs of Kenya. Technical Handbook No. 25. World Agroforestry CentreEastern and Central Africa Regional Programme (ICRAFECA), Nairobi, Kenya.

McCune B, Mefford MJ (1999) PC ORD for Windows Version 4.0. Multivariate analysis of ecological data. MjM Software, Gleneden Beach

Mekonnen K, Yohannes T, Glatzel G, Amha Y (2006) Performance of eight tree species in the Highland vertisols of Central Ethiopia: growth, foliage nutrient concentration and effect on soil chemical properties. New Forest 32:285-298

Mengistu S, Keftasa D, Yami A (2002) Productivity of four Sesbania species on two soil types in Ethiopia. Agrofor Syst 54:235-244

Mengistu T, Teketay D, Hulten H, Yemshaw Y (2005) The role of enclosures in the recovery of woody vegetation in degraded dryland hillsides of Central and Northern Ethiopia. J Arid Environ 60:259-281

Moeremans C (2007) An ecological and socio-economic study of woody species in the context of land degradation in Tigray, Northern Ethiopia. MSc thesis. KULeuven, Leuven, Belgium.
Negussie A, Aerts R, Gebrehiwot K, Muys B (2008) Seedling mortality causes recruitment limitation of Boswellia papyrifera in northern Ethiopia. J Arid Environ 72:378383

Nilaweera NS, Nutalaya P (1999) Role of tree roots in slope stabilization. Bull Eng Geol Environ 57:337-342

Noad T, Birnie A (1989) Trees of Kenya. Nairobi, Kenya

Nyssen J, Poesen J, Moeyersons J, Luyten E, Veyret-Picot M, Deckers J, Haile M, Govers G (2002) Impact of road building on gully erosion risk - a case study from the Northern Ethiopian highlands. Earth Surf Proc Land 27:1267-1283

Nyssen J, Veyret-Picot M, Poesen J, Moeyersons J, Haile M, Deckers J, Govers G (2004) The effectiveness of loose rock check dams for gully control in Tigray, northern Ethiopia. Soil Use Manag 20:55-64

Nyssen J, Vandenreyken H, Poesen J, Moeyersons J, Deckers J, Haile M, Salles C, Govers G (2005) Rainfall erosivity and variability in the northern Ethiopian highlands. J Hydrol 311:172-187

Nyssen J, Naudts J, De Geyndt K, Haile M, Poesen J, Moeyersons J, Deckers J (2008) Soils and land use in the Tigray Highlands (northern Ethiopia). Land Degrad Dev 19:257-274

Poesen J, Nachtergaele J, Verstraeten G, Valentin C (2003) Gully erosion and environmental change: importance and research needs. Catena 50:91-133

Quinton J, Morgan R, Archer N, Hall G, Green A (2002) Bioengineering principles and desertification mitigation. In: Brandt J, Thornes J (eds) Mediterranean desertification and land use. Wiley, Chichester, pp 137-168

Read J, Stokes A (2006) Plant biomechanics in an ecological context. Am J Bot 93:1546-1565

Reubens B, Poesen J, Danjon F, Geudens G, Muys B (2007) The role of fine and coarse roots in shallow slope stability and soil erosion control with a focus on root system architecture: a review. Trees 21:385-402

Reubens B, Pannemans B, Danjon F, De Proft M, De Baets S, De Baerdemaeker J, Poesen J, Muys B (2009) The effect of mechanical stimulation on root and shoot development of young containerized Quercus robur and Robinia pseudoacacia trees. doi:10.1007/s00468-009-0360-x

Ribolzi O, Hermida M, Karambiri H, Delhoume JP, Thiombiano L (2006) Effects of aeolian processes on water infiltration in sandy Sahelian rangeland in Burkina Faso. Catena 67:145154

Roose E, Chebbani R, Bourougaa L (2000) Ravinement en Algérie: Typologie, facteurs de contrôle, quantification et réhabilitation. Sécheresse 11:317-326

Royal Botanic Gardens (2007) SEPASAL, Survey of economic plants for arid and semi-arid lands [on line]. Available at http://www.rbgkew.org.uk/ceb/sepasal. [Accessed July 2008]

Sanchez-Gomez D, Zavala MA, Valladares F (2008) Functional traits and plasticity linked to seedlings' performance under shade and drought in Mediterranean woody species. Annals of Forest Science 65

Segers K, Dessein J, Nyssen J, Haile M, Deckers J (2008) Developers and farmers intertwining interventions: the case of rainwater harvesting and food-for-work in Degua Temben, Tigray, Ethiopia. Int J Agr Sust 6:173-182 
Sheng JA, Liao AZ (1997) Erosion control in South China. Catena 29:211-221

Siegel S, Castellan NJ (1988) Non-parametric statistics for the behavioral sciences. McGraw-Hill book company, New York

Sileshi G, Maghembe JA, Rao MR, Ogol CK, Sithanantham S (2000) Insects feeding on Sesbania species in natural stands and agroforestry systems in southern Malawi. Agrofor Syst 49:41-52

Taddese G (2001) Land degradation - a challenge to Ethiopia. Environ Manage 27:815-824

Taddese G, Saleem MAM, Abyie A, Wagnew A (2002) Impact of grazing on plant species richness, plant biomass, plant attribute, and soil physical and hydrological properties of Vertisol in East African highlands. Environ Manage 29:279-289

Turnbull LA, Paul-Victor C, Schmid B, Purves DW (2008) Growth rates, seed size and physiology: do small-seeded species really grow faster. Ecology 89:1352-1363

West DH, Chappelka AH, Tilt KM, Ponder HG, Williams JD (1999) Effect of tree shelters on survival, growth and wood quality of 11 tree species commonly planted in the southern United States. J Arboric 25:69-75

Wagner W, Herbst DR, Sohmer SH (1999) Manual of the flowering plants of Hawaii. Bernice P. Bishop Museum special publication. University of Hawaii Press/Bishop Museum Press, Honolulu

Wardman A, Salas LG (1991) The implementation of antierosion techniques in the Sahel: a case study from Kaya, Burkina Faso. J Dev Areas 26:65-80

Windey J (2007) Characteristics of belowground biomass of woody species important for erosion control in Tigray, northern Ethiopia. MSc thesis. KULeuven, Leuven, Belgium

World Agroforestry Centre (2002) Agroforestree Database. Nairobi, Kenya. Available at http://www.worldagrofores try.org/sites/TreeDBS/Aft.asp. [Accessed 11 Aug. 2008]

Xu XL, Ma KM, Fu BJ, Song CJ, Liu W (2008) Influence of three plant species with different morphologies on water runoff and soil loss in a dry-warm river valley, SW China. For Ecol Manag 256:656-663 